\title{
Collusion and dynamic (under-) investment in quality
}

\author{
Volker Nocke*
}

In a dynamic game of investment in product quality, I investigate whether collusive underinvestment equilibria can be supported by the threat of escalation in investment outlays. When there are no spillovers, underinvestment equilibria exist even though, by deviating, a firm can gain a persistent strategic advantage. When there are strong spillovers, underinvestment equilibria fail to exist. A weakening of patent protection can thus lead to more investment in equilibrium. A "nonfragmentation" result is shown to hold: in all free-entry equilibria, industry concentration is bounded away from zero, no matter how large the market, and despite the existence of underinvestment equilibria.

\section{Introduction}

- In recent years, antitrust authorities have devoted much of their attention and resources to fast-growing innovative industries such as computing, pharmaceuticals, and healthcare. ${ }^{1}$ In these cases, the complaint often explicitly focuses on the dynamic nature of competition in such markets. As Evans and Schmalensee (2001) point out, static price/output competition in the market is arguably less important in innovative industries than dynamic competition for the market. In such industries, antitrust authorities should thus be more concerned with adverse effects on investment and innovation rather than on prices or quantities.

This article is concerned with collusion in investment levels in industries in which firms invest to improve their product quality. Indeed, oligopolistic firms often invest in order to gain a competitive advantage over their rivals, and thereby impose a negative externality on their rivals. Because of this business-stealing effect, noncooperative investment levels tend to be higher than those that maximize firms' joint profits. Hence, firms have an incentive to coordinate on low investment outlays. Such underinvestment may be sustained by the threat of an escalation in investment outlays in the event of a deviation.

While a number of articles take seriously the fact that competition in innovative industries is dynamic in nature, the literature has so far ignored the possibility of collusion in investment levels.

*University of Oxford; volker.nocke@economics.ox.ac.uk.

This article is based on chapter 2 of my Ph.D. thesis submitted at the London School of Economics. Earlier versions were circulated and presented under the title Underinvestment and Market Structure. I am indebted to John Sutton for his advice and encouragement. I would also like to thank the Editor, two anonymous referees, Markus Brunnermeier, George Mailath, Adam Ostaszewski, Martin Peitz, Sönje Reiche, Patrick Rey, Rani Spiegler, Jean Tirole, and Lucy White, as well as seminar participants at various universities and conferences for helpful comments. Finally, I gratefully acknowledge financial support by the National Science Foundation (grant no. SES-0422778).

${ }^{1}$ See, for example, Morse (1998) and Kwoka and White (2004). 
On the other hand, the existing literature on collusion focuses exclusively on collusion in transitory economic variables such as prices and quantities. This article takes a step towards integrating these two approaches and so providing a tool for analyzing competition in such dynamic markets.

In innovative industries, endogenous industry dynamics are important in that current investments in product or process innovation change not only current but also future market conditions. Since it is difficult for a firm to "unlearn" the result of its investments in quality, these investments have a permanent impact on firms' payoffs. This suggests that one should model dynamic competition in product quality as a dynamic investment game rather than as an infinitely repeated game since, in the latter, tangible market conditions are assumed to be stationary.

While there is a large literature on collusion in infinitely repeated games, dynamic investment games - in which current actions have tangible effects on future payoffs - are much less well understood. From a series of folk theorems it is well known that collusive equilibria exist in infinitely repeated games, provided the discount factor is sufficiently large. In a dynamic investment game, however, a deviant firm can change future market conditions by outspending its rivals and thereby gain a persistent strategic advantage. The existence of tacitly collusive underinvestment equilibria in dynamic investment games is therefore not obviously ensured.

In this article, I analyze a dynamic game of investment in product quality. Such investment might be thought of as quality-improving R\&D (e.g., Sutton, 1998) or as persuasive advertising (e.g., Sutton, 1991). I find that the existence of underinvestment equilibria depends crucially on the presence of spillover effects in the appropriation of the benefits from investment. When there are no spillovers from investment, underinvestment equilibria exist as long as the investment cost function is sufficiently elastic, and the discount factor sufficiently large. However, when there are strong spillovers, underinvestment equilibria fail to exist, even for discount factors arbitrarily close to unity. To the extent that an increase in patent protection reduces spillovers from investment, stronger patent protection may paradoxically result in less investment in equilibrium. The reason is that firms have less incentive to invest when they cannot fully appropriate the benefits, and this reduction in the incentives to invest destroys the punishment mechanism through which underinvestment is supported in equilibrium. This should be of concern for antitrust authorities since, as I show, underinvestment unambiguously reduces welfare.

On the positive side, the existence of underinvestment equilibria in my model (when there are no spillovers) raises an important question for the analysis of market structure. Since R\&D- and advertising-intensive industries are "endogenous sunk cost" industries (Sutton, 1991), the question arises whether the "finiteness property" or "nonfragmentation result" (Shaked and Sutton, 1987) holds in my dynamic investment game; that is, whether or not in any free entry equilibrium, the number of active firms remains finite, even as the market grows without bound.

Yet competition in endogenous sunk cost industries is dynamic in nature, and the nonfragmentation result has been obtained solely in static stage-game models. It is an open question whether this result still holds in dynamic models. In a static model, the finiteness property is proved by showing that there always exists a profitable deviation for some firm in a large and fragmented market. This deviation consists of a sufficient rise in investment outlays so as to capture a positive market share. In a dynamic model, however, such a single deviation might be followed by a severe (and possibly complex) "punishment" strategy by rival firms, making the deviation potentially unprofitable. Thus it is not clear whether the finiteness property will still hold in cases where underinvestment equilibria can be sustained through such punishment strategies. Nevertheless I am able to show that the result is indeed robust: in all equilibria of my dynamic investment game, the number of firms must remain finite - there is a lower bound to concentration in such dynamic markets.

Related literature. In addition to Sutton's work on industrial market structure (Shaked and Sutton, 1987; Sutton, 1991, 1998, forthcoming), this article is related to the literature on dynamic investment games in industrial organization; see, for example, Reinganum (1989), Segal and Whinston (2003) on dynamic R\&D; Budd, Harris, and Vickers (1993) and Cabral and Riordan (1994) on increasing dominance. This literature has widely ignored the possibility of tacit collusion 
in investment levels, sustained by the threat of an escalation in investment outlays. A notable exception is the model of investment in capacity by Fudenberg and Tirole (1983). ${ }^{2}$ But in their continuous-time game the existence of underinvestment equilibria is trivially ensured (even for arbitrarily small discount factors) since, by construction, a deviant firm cannot leapfrog its rivals and therefore never get a persistent strategic advantage. Moreover, as I will discuss, there is a subtle but important difference between sustaining underinvestment in capacity and underinvestment in product quality, which is closely connected to Sutton's (1991) distinction between "exogenous" and "endogenous" sunk cost industries. Once a firm has sufficient capacity to flood the entire market, it has no incentive to build more capacity, no matter how large the discount factor, and so capacity costs become less and less important (relative to revenues) as the discount factor becomes large. In contrast, since consumers always prefer higher-quality products to lowerquality products, noncooperative incentives to invest in quality increase without bound as the discount factor becomes large. This implies that the threat of escalation in investment outlayswhich is used to sustain collusive underinvestment-becomes larger, the larger is the discount factor. Consequently, it is possible to sustain collusive underinvestment in quality even though by deviating a firm can get a persistent strategic advantage over its rivals. This article thus shows that it is not innocuous to lump together different types of dynamic games under the general heading "dynamic investment games." Building on the framework developed by Ericson and Pakes (1995), there is also a recent and growing literature that analyzes industry dynamics using numerical methods; e.g., Gowrisankaran (1999) on horizontal mergers, Besanko and Doraszelski (2004) on capacity investment, and Doraszelski and Markovich (2005) on advertising. Restricting attention to Markov-perfect equilibria, this literature does not consider collusion. Two recent exceptions are Fershtman and Pakes (2000) and de Roos (2004). However, these authors analyze collusion in transitory economic variables (prices or quantities) that do not affect tangible market conditions, and they therefore need to introduce an extraneous state variable that indicates whether a firm has deviated in the past. Building on Fudenberg and Tirole (1983), I show that collusion in investment levels can be sustained even when restricting attention to Markov-perfect equilibria, and even without artificially expanding the state space.

The article is laid out as follows. In Section 2, I present the basic two-firm version of the model when there are no spillovers. The noncollusive benchmark equilibrium and the existence of collusive underinvestment equilibria are analyzed in Section 3. In Section 4, I compare welfare in the different types of equilibria. In Section 5, I introduce spillovers into the model, and re-visit the existence of collusive underinvestment equilibria. In Section 6, I turn to the analysis of market structure, and investigate whether the two-firm underinvestment equilibria are stable with respect to further entry, independently of market size and entry costs. In Section 7, I analyze whether the finiteness property holds in the dynamic game, despite the existence of underinvestment equilibria. Finally, Section 8 concludes. Proofs not found in the Appendix can be found at the Web Appendix (www.rje.org/main/sup-matl.html).

\section{The basic model}

- In this section, I present the basic dynamic model without spillovers. There are two firms, each offering one variety of a quality good. In each period, firms first decide how much to invest. Then, they compete in quantities. A firm's investment persistently raises consumers' willingnessto-pay for the firm's offering, and so improves the firm's competitive position relative to that of its rival. Under my preferred interpretation (which I will henceforth adopt), investment is in quality-improving R\&D (with deterministic outcome) as, for example, in Sutton (1998). Under my alternative interpretation, which the reader may keep in mind, investment is in persuasive advertising or in the stock of "goodwill." ${ }^{3}$ In this section, I do not allow for entry of a third firm.

${ }^{2}$ Dutta (1995) provides an approximate folk theorem for stochastic games. Nevertheless, as I will show, underinvestment cannot be sustained as an equilibrium outcome in my model if there are strong spillovers, no matter how large the discount factor.

3 The goodwill approach to advertising goes back to Nerlove and Arrow (1962). 
The topic of potential entry, which is essential for the analysis of market structure, will be taken up in Sections 6 and 7.

Consider a dynamic infinite-horizon version of Sutton's (1991) model of investment in product quality. Time is discrete and indexed by $t$. There are two firms, $i=1,2$, and $N$ consumers indexed by $\ell$. Consumer preferences are defined over a quality good, produced in the industry under consideration, and an 'outside good' (or Hicksian composite commodity) whose price and attributes are assumed to be constant over time. There are two varieties of the quality good on offer, one by each firm. Consumers value quality. Specifically, consumer $\ell$ 's utility in period $t$ is given by

$$
U^{\ell}\left(x_{t}^{\ell, 1}, x_{t}^{\ell, 2}, y_{t}^{\ell}\right)= \begin{cases}\alpha^{\ell} \ln \left(\sum_{i=1}^{2} u_{t}^{i} x_{t}^{\ell, i}\right)+y_{t}^{\ell} & \text { if } \sum_{i=1}^{2} u_{t}^{i} x_{t}^{\ell, i}>0, \\ -\infty & \text { otherwise, }\end{cases}
$$

where $x_{t}^{\ell, i} \geq 0$ and $y_{t}^{\ell} \geq 0$ are the quantities consumed of firm $i$ 's variety of the quality good and the outside good, respectively; $u_{t}^{i}$ is the quality of firm $i$ 's offering in period $t$, and $\alpha^{\ell}>0$ is a parameter that measures the intensity of consumer $\ell$ 's preferences for the quality good. Consumer income in each period is denoted by $m^{\ell}$. I assume $m^{\ell}>\alpha^{\ell}$, which ensures that each consumer $\ell$ consumes a positive amount of the outside good. The quality index is normalized so that the basic version of the quality good is of quality 1 , i.e., $u_{t}^{i} \geq 1$. Note that, for $x_{t}^{\ell, i}>0$, utility is strictly increasing in quality $u_{t}^{i}$.

In the quality good industry, firm $i$ 's period- $t$ cost of investment in quality improvement is given by

$$
F\left(u_{t}^{i} ; u_{t-1}^{i}\right)=F_{0}\left(u_{t}^{i}\right)^{\beta}-F_{0}\left(u_{t-1}^{i}\right)^{\beta},
$$

where $F_{0}>0$ and $\beta \geq 2$ are parameters that measure the effectiveness of spending in raising consumers' willingness-to-pay. (The assumption $\beta \geq 2$ ensures that the firm's investment problem is well behaved.) Without loss of generality, normalize the cost parameter $F_{0} \equiv 1$. The effectiveness of quality investment is subject to diminishing returns; there are no "adjustment costs." Observe that $F(u ; u)=0$ : investment costs are zero if a firm does not raise the quality of its product. Further, assume that quality does not depreciate, and $u_{t}^{i} \geq u_{t-1}^{i}$. Both firms have constant and strictly positive marginal costs of production, $c>0$, which are independent of quality.

The timing of the game is as follows. In each period, there are two stages. In the first stage, firms 1 and 2 simultaneously decide whether and how much to invest in quality improvement, and incur the fixed investment outlays. In the second stage, the two firms simultaneously decide how much to produce (quantity competition); consumers, taking price as given, decide how much to consume of each product, and prices are such that markets clear. Firm $i$ 's second-stage profit in period $t$ is therefore given by $\left(p_{t}^{i}-c\right) x_{t}^{i}$, where $p_{t}^{i}$ and $x_{t}^{i}$ are price and quantity, respectively; firm $i$ 's net profit in period $t$ is then $\left(p_{t}^{i}-c\right) x_{t}^{i}-F\left(u_{t}^{i} ; u_{t-1}^{i}\right)$.

Consumers maximize the discounted value of per-period utility, taking the sequence of prices and qualities as given. There is no saving or storing. Consequently, consumers' decision problem simplifies to myopic period-by-period utility maximization. Firms maximize the discounted sum of profits. The common discount factor is denoted by $\delta \in(0,1)$. All parameters of the model, and all moves in past periods and stages, are assumed to be common knowledge.

In the equilibrium analysis, I confine attention to Markov strategies that depend on the tangible state only, and so the relevant solution concept is that of Markov perfect equilibrium (MPE). Recall that every MPE is a subgame-perfect equilibrium (SPE), even when strategies are not restricted to be Markov. The idea of this approach is that history should influence current actions only if it has a direct effect on the current environment, but not because players believe that history matters. (In the spirit of this approach, I refrain from introducing extraneous state variables that keep track of past deviations from equilibrium play.) Furthermore, the Markov restriction greatly simplifies the equilibrium analysis; as Shapiro (1989) notes, it allows me to 
focus on strategic aspects of commitment. (For further justification of the approach, see Maskin and Tirole, 1988.)

At each decision node, the state of the industry can be summarized by the current pair of qualities $\left(u^{1}, u^{2}\right) \in[1, \infty)^{2}$. Firm $i$ 's (pure) Markov action rule at stage 1 in period $t$ is a mapping $s^{i}:\left(u_{t-1}^{1}, u_{t-1}^{2}\right) \longmapsto u_{t}^{i} \in\left[u_{t-1}^{i}, \infty\right)$; at the second stage of the same period its action rule is a mapping $\widetilde{s}^{i}:\left(u_{t}^{1}, u_{t}^{2}\right) \longmapsto x_{t}^{i} \in[0, \infty)$.

\section{Equilibrium analysis: escalation and underinvestment}

In this section, I turn to the equilibrium analysis of the basic model without spillovers. I first show the existence of a noncollusive investment equilibrium in which firms engage in an escalation of investment outlays. The central result of this section is developed later in this section, where I show the existence of a collusive underinvestment equilibrium. Underinvestment can be supported in equilibrium by the credible threat of escalation in case of deviation, even though by deviating a firm can get a persistent strategic advantage over its rival.

Competition in quantities. Consider first the second stage in any given period. Since quantity choice does not affect future payoff-relevant variables (qualities), the Markov restriction allows me to analyze the quantity-setting game as a one-shot game. It is then straightforward to solve for the Nash equilibrium in quantities.

Lemma 1. For any state $\left(u^{1}, u^{2}\right)$, there exists a unique stage-2 Nash equilibrium. Firm $i$ 's equilibrium gross profit is given by

$$
\pi^{i}\left(u^{1}, u^{2}\right)=S\left(\frac{u^{i}}{u^{1}+u^{2}}\right)^{2}
$$

where $S \equiv \sum_{i=1}^{2} p^{i} x^{i}=\sum_{\ell=1}^{N} \alpha^{\ell}$ is a measure of market size. ${ }^{4}$ In equilibrium, consumer $\ell$ 's period- $t$ utility is equal to

$$
U^{\ell}\left(u_{t}^{1}, u_{t}^{2}\right)=\alpha^{\ell} \ln \left\{\frac{\alpha^{\ell}}{c}\left(\frac{u_{t}^{1} u_{t}^{2}}{u_{t}^{1}+u_{t}^{2}}\right)\right\}+m^{\ell}-\alpha^{\ell} .
$$

In equilibrium, each firm sets the same quantity, and prices adjust such that each consumer is indifferent between the two varieties. The lemma shows that firm $i$ 's stage-2 profit depends on $u^{i} / u^{j}$, the ratio of qualities; multiplying both qualities by the same factor does not affect profits. The model thus allows me to focus on the business-stealing effect of investment. Observe also that each firm's stage- 2 equilibrium profit has the appealing property that it is increasing in the firm's own quality, and decreasing in the rival's quality; this differs from models of pure vertical product differentiation. ${ }^{5}$

Dynamic investment: escalation. Having solved for stage- 2 equilibrium as a function of the pair of current qualities, the dynamic game can now be analyzed as an infinite-horizon investment game in which, in each period, the two firms simultaneously invest in quality, and firm $i$ 's payoff in period $t$ is given by

$$
\Pi^{i}\left(u_{t}^{1}, u_{t}^{2}\right)=\pi^{i}\left(u_{t}^{1}, u_{t}^{2}\right)-F\left(u_{t}^{i} ; u_{t-1}^{i}\right) .
$$

Infinite-horizon dynamic games are notoriously difficult to analyze since they neither have a stationary structure (like infinitely repeated games), nor can be solved by backward induction

\footnotetext{
${ }^{4}$ What matters for firms' investment choice is only the ratio $S / F_{0}$. Given the normalization of $F_{0}$, market size $S$ should henceforth be interpreted relative to this cost parameter.

${ }^{5}$ If I introduced horizontal product differentiation (in addition to potential quality differences), then the solved-out second-stage profit function would share the same qualitative features under price and quantity competition: each firm's gross profit would increase in its own quality, and decrease in its rival's quality.
} 
(like finite-horizon games). However, a class of subgame-perfect equilibria can be found in my game by first viewing each firm's sequence of investment decisions as a single-player dynamic optimization problem, holding the quality of the other player fixed. In this way, I can determine a region in the space of qualities (state variables) such that neither firm wants to invest further, given that its rival will never invest again. Since this region is associated with high quality levels, I can then, in a backward induction fashion, proceed to determine equilibria for subgames starting at lower quality levels. ${ }^{6}$

Suppose that the current quality of firm $i$ 's offering is given by $u_{-1}^{i} \geq 1$. Holding firm $j$ 's quality $u^{j}$ fixed forever, firm $i$ 's optimization problem is then given by

$$
\max _{\left\{u_{\tau}^{i} \geq u_{\tau-1}^{i}\right\}} \sum_{\tau=0}^{\infty} \delta^{\tau} \Pi^{i}\left(u_{\tau}^{1}, u_{\tau}^{2}\right),
$$

where $u_{\tau}^{j}=u^{j}$ for all $\tau \geq 0$. Rewriting, the program becomes

$$
\max _{\left\{u_{\tau}^{i} \geq u_{\tau-1}^{i}\right\}} \sum_{\tau=0}^{\infty} \delta^{\tau}\left\{S\left(\frac{u_{\tau}^{i}}{u_{\tau}^{i}+u^{j}}\right)^{2}-(1-\delta)\left(u_{\tau}^{i}\right)^{\beta}\right\}+\left(u_{-1}^{i}\right)^{\beta} .
$$

Due to the additive separability of the investment cost function, the dynamics are conveniently simple: given that its rival will never invest again, it is optimal for firm $i$ to do all its investment at once, and then cease investing forever. To see this, note that the optimal choice of $u_{\tau}^{i}$ maximizes the expression in curly brackets, and is thus independent of time $\tau$. Firm $i$ 's optimization problem can thus be written as

$$
\max _{u^{i} \geq u_{-1}^{i}} \frac{S}{1-\delta}\left(\frac{u^{i}}{u^{i}+u^{j}}\right)^{2}-\left(u^{i}\right)^{\beta}+\left(u_{-1}^{i}\right)^{\beta}
$$

I call the solution to (7) firm $i$ 's "stationary best reply to $u^{j}$."

Lemma 2. Firm $i$ 's stationary best reply to $u^{j}$ equals its current quality $u_{-1}^{i}$ if

$$
\frac{2 S}{1-\delta} \frac{u_{-1}^{i} u^{j}}{\left(u_{-1}^{i}+u^{j}\right)^{3}}-\beta\left(u_{-1}^{i}\right)^{\beta-1} \leq 0,
$$

and the unique solution $\widehat{u}\left(u^{j}\right)$ to the first-order condition of (7),

$$
\frac{2 S}{1-\delta} \frac{\widehat{u}\left(u^{j}\right) u^{j}}{\left(\widehat{u}\left(u^{j}\right)+u^{j}\right)^{3}}-\beta\left(\widehat{u}\left(u^{j}\right)\right)^{\beta-1}=0
$$

otherwise. Hence, firm $i$ 's stationary best reply to $u^{j}$ is given by $\max \left\{u_{-1}^{i}, \widehat{u}\left(u^{j}\right)\right\}$.

I call $\widehat{u}(\cdot)$ the "interior stationary best-reply function." Due to symmetry, this function coincides for both firms.

Lemma 3. There is a unique intersection of the two interior stationary best-reply curves in $(0, \infty)^{2}$. This intersection corresponds to a symmetric state, $(\bar{u}, \bar{u})$, where $\bar{u}=\widehat{u}(\bar{u})$ is given by

$$
\bar{u}=\left(\frac{S}{4(1-\delta) \beta}\right)^{1 / \beta}
$$

For $u^{j} \geq \bar{u}$, firm $i$ 's interior stationary best reply to $u^{j}, \widehat{u}\left(u^{j}\right)$, is strictly decreasing in $u^{j}$.

${ }^{6}$ This construction is facilitated by the assumption of no depreciation, which implies a unidirectional state-to-state transition, $u_{t+1}^{i} \geq u_{t}^{i}$.

(c) RAND 2007. 


\section{FIGURE 1}

\section{STATIONARY REACTION CURVES}

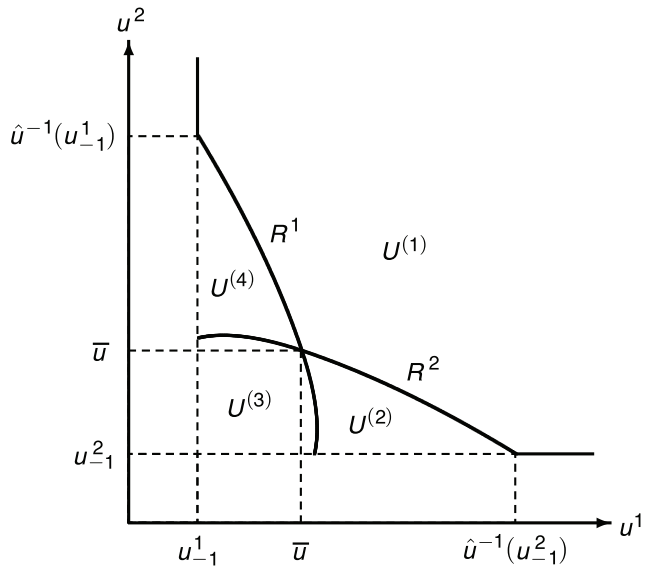

Lemma 3 implies that if $\left(u_{-1}^{1}, u_{-1}^{2}\right) \leq(\bar{u}, \bar{u})$, then $(\bar{u}, \bar{u})$ is the unique intersection of the two stationary reaction curves. The stationary reaction curves are illustrated in Figure 1.

I can now define four regions in the space of qualities. In region $1, U^{(1)}$, the qualities of both firms are above their respective interior best replies:

$$
U^{(1)} \equiv\left\{\left(u^{1}, u^{2}\right) \in[1, \infty)^{2} \mid u^{i} \geq \widehat{u}\left(u^{j}\right), i, j=1,2, i \neq j\right\}
$$

Graphically, this is the region above the outer envelope of the two interior best-reply curves. Region 2 consists of the pairs of qualities such that firm 1's quality is above $\bar{u}$ and firm 2's quality is below its interior best reply:

$$
U^{(2)} \equiv\left\{\left(u^{1}, u^{2}\right) \in[1, \infty)^{2} \mid u^{1} \geq \bar{u}, u^{2}<\widehat{u}\left(u^{1}\right)\right\} .
$$

Region 4 is defined in the same way as region 2, but firm indices are reversed. Finally, region 3 encompasses all states that are below the symmetric intersection:

$$
U^{(3)} \equiv\left\{\left(u^{1}, u^{2}\right) \in[1, \infty)^{2} \mid u^{i}<\bar{u}, i=1,2\right\} .
$$

I am now in the position to determine an MPE of the dynamic investment game, starting from any state of the industry.

Proposition 1. The following set of mappings from the current state, $\left(u_{t-1}^{1}, u_{t-1}^{2}\right)$, to the space of feasible actions, $\left[u_{t-1}^{i}, \infty\right)$, induces a pure strategy for each firm $i$. The induced strategy profile, $\Sigma^{\text {esc }}$, forms an MPE starting from any state.

(i) If $\left(u_{t-1}^{1}, u_{t-1}^{2}\right) \in U^{(1)}$, then $s^{i}\left(u_{t-1}^{1}, u_{t-1}^{2}\right)=u_{t-1}^{i}, i=1,2$ (no investment).

(ii) If $\left(u_{t-1}^{1}, u_{t-1}^{2}\right) \in U^{(2)}$, then $s^{1}\left(u_{t-1}^{1}, u_{t-1}^{2}\right)=u_{t-1}^{1}$, and $s^{2}\left(u_{t-1}^{1}, u_{t-1}^{2}\right)=\widehat{u}\left(u_{t-1}^{1}\right)$ (only firm 2 invests).

(iii) If $\left(u_{t-1}^{1}, u_{t-1}^{2}\right) \in U^{(3)}$, then $s^{i}\left(u_{t-1}^{1}, u_{t-1}^{2}\right)=\bar{u}, i=1,2$ (both firms invest up to $\bar{u}$ ).

(iv) If $\left(u_{t-1}^{1}, u_{t-1}^{2}\right) \in U^{(4)}$, then $s^{1}\left(u_{t-1}^{1}, u_{t-1}^{2}\right)=\widehat{u}\left(u_{t-1}^{2}\right)$, and $s^{2}\left(u_{t-1}^{1}, u_{t-1}^{2}\right)=u_{t-1}^{2}$ (only firm 1 invests).

Proof. Per-period net profits, $\Pi^{i}\left(u_{t}^{1}, u_{t}^{2}\right)$, are bounded above (by $S$ ) and firms discount future profits. Hence, the one-stage deviation principle for infinite-horizon games applies (Fudenberg 
and Tirole, 1991): it is impossible to gain by an infinite sequence of deviations when there is no profitable single one-stage deviation.

(i) Suppose first the current state satisfies $\left(u_{-1}^{1}, u_{-1}^{2}\right) \in U^{(1)}$. According to $\Sigma^{\text {esc }}$, neither firm invests in quality, and so the state of the industry stays forever at $\left(u_{-1}^{1}, u_{-1}^{2}\right) \in U^{(1)}$ : no firm will invest again along the equilibrium path. Note that since $u_{-1}^{i} \geq \widehat{u}\left(u_{-1}^{j}\right), i=1,2, i \neq j$, each firm $i$ chooses the stationary best reply to its rival's quality $u_{-1}^{j}$. Thus, by definition of a stationary best reply, any deviation that does not induce the nondeviant rival to invest again in a future period cannot be profitable. Recall that a firm's stage-2 profit is decreasing in its rival's quality. This implies that the payoff from a deviation that induces the nondeviant rival to invest in some future period is bounded from above by the payoff that the deviant firm would obtain if its nondeviant rival did not invest again. ${ }^{7}$ Hence, such a deviation cannot be profitable either.

(ii) Suppose now the current state satisfies $\left(u_{-1}^{1}, u_{-1}^{2}\right) \in U^{(2)}$. (The argument for case (iii), $\left(u_{-1}^{1}, u_{-1}^{2}\right) \in U^{(4)}$, is analogous.) According to $\Sigma^{\text {esc }}$, only firm 2 invests by choosing quality $u_{0}^{2}=\widehat{u}\left(u_{-1}^{1}\right)$, the state of the industry moves to $\left(u_{-1}^{1}, \widehat{u}\left(u_{-1}^{1}\right)\right) \in U^{(1)}$, and stays there forever: no firm will invest again along the equilibrium path. Note that each firm chooses the stationary best reply to its rival's (new) quality: firm 2 chooses $u_{0}^{2}=\widehat{u}\left(u_{-1}^{1}\right)>u_{-1}^{2}$, while firm 1 chooses $u_{0}^{1}=u_{-1}^{1} \geq \bar{u} \geq \widehat{u}\left(u_{0}^{2}\right)$. Hence, using the same argument as in case (i), there is no profitable deviation.

(iv) Finally, suppose the current state satisfies $\left(u_{-1}^{1}, u_{-1}^{2}\right) \in U^{(4)}$. In this case, the strategy profile $\Sigma^{\text {esc }}$ prescribes that both firms invest up to quality $\bar{u}$, and the state of the industry stays forever after at $(\bar{u}, \bar{u}) \in U^{(1)}$ : neither firm invests again along the equilibrium path. Note that each firm $i$ chooses its stationary best reply to its rival's (new) quality: $\widehat{u}(\bar{u})=\bar{u}>u_{-1}^{i}$. Hence, using the same argument as in case (i), there is no profitable deviation.

Comparative statics results are easily obtained. Investment along the equilibrium path is weakly increasing in the discount factor $\delta$ and market size $S$, and weakly decreasing in the cost parameter $\beta$. In the remainder of the article, the investment equilibrium $\sum^{\text {esc }}$ will serve as the benchmark noncollusive equilibrium. I will call "underinvestment equilibrium" any equilibrium that exhibits less investment along the equilibrium path than this benchmark equilibrium.

Dynamic investment: underinvestment. Along the equilibrium path induced by strategy profile $\Sigma^{\text {esc }}$, each firm engages in an "escalation" of investment outlays up to quality $\bar{u}$ if the current state is "below" $(\bar{u}, \bar{u})$. In particular, if the current state is $(u, u)<(\bar{u}, \bar{u})$, then the state of the industry will move to $(\bar{u}, \bar{u})$, and stay there forever, even though both firms would prefer to remain at $(u, u)$. (Since the stage-2 profit function, (3), depends on the ratio of qualities only, the stage-2 profit is the same in both states but, of course, moving to the higher state involves spending on R\&D or advertising.) That is, both firms have an incentive to coordinate not to invest at all in order to avoid an escalation of investment outlays, which is wasteful from their point of view.

Since I have established the existence of an MPE exhibiting escalation of investment, it might be possible to support tacitly collusive equilibria, exhibiting little or no investment, by the threat of escalation in case of deviation. Formally, I consider a (symmetric) strategy profile, denoted by $\Sigma^{\text {coll }}(u), u<\bar{u}$, that is induced by the following action rules. Given an initial state $\left(u_{-1}^{1}, u_{-1}^{2}\right) \leq(u, u)<(\bar{u}, \bar{u}), s^{i}\left(u_{-1}^{1}, u_{-1}^{2}\right)=u$. Moreover, $s^{i}(u, u)=u$. However, if $\left(u_{t-1}^{1}, u_{t-1}^{2}\right) \notin\left\{(u, u),\left(u_{-1}^{1}, u_{-1}^{2}\right)\right\}$, then $s^{i}\left(u_{t-1}^{1}, u_{t-1}^{2}\right)$ is the same as under $\Sigma^{\text {esc }}$. That is, $\Sigma^{\text {coll }}(u)$ prescribes that, starting from some initial state, each firm invests up to quality level $u$; in state $(u, u)$, no firm invests any further; in any other state, each firm chooses the same action as in the noncollusive equilibrium $\Sigma^{\text {esc }}$.

${ }^{7}$ In fact, since $\widehat{u}\left(u^{j}\right)$ is decreasing in $u^{j}$ for $u^{j} \geq \bar{u}$ and since $u_{t}^{i} \geq u_{t-1}^{i}$, a firm cannot induce its rival to invest in some future period: according to $\Sigma^{\mathrm{esc}}, U^{(1)}$ is an "absorbing" region.

(c) RAND 2007 . 
A priori, it is not obvious whether such an underinvestment equilibrium exists. First, suppose the discount factor is zero and the current state is $(u, u)<(\bar{u}, \bar{u})$. Then, clearly, a deviation to $\widehat{u}(u)>u$ is profitable since the deviant firm does not care about future costs and stage- 2 profits. Hence, by continuity of discounted payoffs in $\delta$, there exists a profitable deviation for discount factors sufficiently small.

Second, suppose the current state is $(u, u)<(\bar{u}, \bar{u})$ and firm $i$ deviates by investing up to quality level $u^{\prime}>\bar{u}$. According to strategy profile $\Sigma^{\text {coll }}(u)$, the nondeviant firm will then, in the following period, react and invest up to $\widehat{u}\left(u^{\prime}\right)$, where $\widehat{u}\left(u^{\prime}\right)<\bar{u}$; no further investment will occur. (By deviating to $u^{\prime} \geq \widehat{u}^{-1}(u)$, firm $i$ can even preempt any reaction by its rival.) Along this path, the deviator will make, in each period, higher stage- 2 profits than at $(u, u)$. That is, by deviating, firm $i$ can get ahead of its rival, and ensure that it will always have the higher quality. These additional stage- 2 profits have to be compared with the associated investment costs that have to be incurred only in the period of deviation. Intuitively, one may expect such a deviation to be profitable for a sufficiently large discount factor. On the other hand, however, the higher is the discount factor, the larger are the returns accruing from investment in quality, and hence the higher is the level of investment associated with $\Sigma^{\mathrm{esc}}$. That is, the larger is $\delta$, the more expensive it is for the deviant firm to ensure itself a persistent strategic advantage over its rival.

The following proposition gives one of the main results of this article.

Proposition 2 (underinvestment). If the discount factor $\delta$ is sufficiently large, underinvestment equilibria exist. In particular, suppose the initial state is given by $\left(u_{-1}^{1}, u_{-1}^{2}\right) \leq(u, u)<(\bar{u}, \bar{u})$. Then there is a threshold discount factor $\widehat{\delta} \in(0,1)$, such that for all $\delta \in(\widehat{\delta}, 1)$, strategy profile $\Sigma^{\text {coll }}(u)$ forms an MPE. ${ }^{8}$

As argued above, the higher is the discount factor $\delta$, the larger is the increase in the discounted sum of stage- 2 profits from deviating to a given quality level $u^{\prime}>\bar{u}$. However, as $\delta$ increases, the stationary reaction curves move outward. Hence, a deviation that ensures a fixed increase in stage-2 profit for all future periods (i.e., a fixed quality ratio $u^{\prime} \widehat{u}\left(u^{\prime}\right)>1$ ) becomes increasingly expensive as $\delta$ becomes large. The proposition shows that this cost effect dominates the stage- 2 profit effect if the investment cost function is sufficiently elastic $\left(\beta \geq 2\right.$, as assumed). ${ }^{9}$

These results are reminiscent of the existence of "early stopping equilibria" in the dynamic model of investment in capacity by Fudenberg and Tirole (1983). ${ }^{10}$ In their continuous-time model, firms face linear investment costs and an exogenous upper bound on the feasible flow of investment at each point in time. ${ }^{11}$ These assumptions trivially imply that a firm cannot leapfrog its rival by deviating. Moreover, in a model of capacity investment, gross profits for both firms can be higher at low capacity levels than at high levels since competition in quantities is more intense when both firms have larger capacities. (This is an important difference to models of investment in quality, where gross profits will, in general, not be higher in lower states; see the remark below.) Hence, in Fudenberg and Tirole's model, underinvestment equilibria trivially exist for all discount factors. To see this, consider two points in the state space, "A" and "B," where A exhibits lower capacity levels than B, but higher stage-2 profits. Suppose further that the noncollusive benchmark equilibrium requires firms to invest from A to B. Clearly, no investment at A can be sustained in equilibrium, independently of the discount factor.

${ }^{8}$ Under the conditions of the proposition, asymmetric underinvestment equilibria exist as well since stage-2 profits are continuous in qualities.

${ }^{9}$ Actually, the effect of an increase in $\beta$ on the profits from deviation is rather subtle; there are two opposing effects. On the one hand, an increase in $\beta$ makes the deviation to a fixed $u^{\prime}$ more expensive; on the other hand, it makes the response of the nondeviant rival less aggressive in that it decreases $\widehat{u}\left(u^{\prime}\right)$ for a given $u^{\prime}$. For any fixed quality ratio $u^{\prime} / \widehat{u}\left(u^{\prime}\right)>1$, one can show that deviation profits are first increasing, and then decreasing, in $\beta$.

${ }^{10}$ Reynolds $(1987,1991)$ re-visits Fudenberg and Tirole's model in a linear-quadratic differential game framework, where capacity depreciates over time.

${ }^{11}$ That is, Fudenberg and Tirole assume the information lag to be extremely short (zero) relative to the speed of investment, in contrast to my model. Their assumption seems to be more reasonable in the context of capacity investment than in the case of investment in quality. 
Remark. There is a subtle but important difference between dynamic investment in capacity and dynamic investment in quality. In the Appendix, I briefly discuss a discrete-time version of Fudenberg and Tirole (1983) that allows for leapfrogging. As shown there, a firm will never want to build more capacity than would be sufficient to serve market demand at a price equal to marginal cost. Hence, investment levels are bounded from above and get dwarfed by the discounted sum of gross profits as the discount factor becomes large, and so, as $\delta \rightarrow 1$, the stationary curves converge to some limiting curves. As I show in the Appendix, sufficiently small capacity levels can therefore not be sustained as a collusive equilibrium outcome by the threat of a reversion to the noncollusive equilibrium in case of deviation, not even as the discount factor becomes large.

In contrast, in this model of investment in quality, each firm can get a competitive advantage over its rival by offering a higher quality than its rival, no matter how large that rival's product quality. Since a firm's incentive to achieve such a competitive advantage increases with the discount factor, the stationary reaction curves do not converge to some limit curves as $\delta \rightarrow 1$, and investment costs do not get dwarfed. Consequently, underinvestment in quality can be supported even though, by deviating, a firm can ensure itself forever higher gross profits. As further discussed in footnote 20 , this difference between investment in capacity and investment in quality is closely connected to Sutton's (1991) distinction between exogenous and endogenous sunk cost industries. ${ }^{12}$

In the analysis conducted so far, I have left out the important issue of potential entry. I will generalize the model so as to allow for potential entry and an arbitrary number of active firms in Sections 6 and 7. But before turning to the analysis of market structure, I will first analyze welfare in the basic model and, then, introduce spillovers.

\section{Welfare analysis}

- The aim of this section is to compare "welfare" in the symmetric investment equilibrium and in an arbitrary (symmetric) underinvestment equilibrium. Any action by antitrust authorities is justified only if collusion in investment reduces welfare. As a welfare measure, choose the sum of discounted profits and discounted utility; call this measure "net surplus." In my setting, this choice is natural and theoretically well justified since consumers have quasilinear preferences: utility is linear in the outside numéraire good, and so there are no income effects of redistributing profits to consumers. ${ }^{13}$

A priori it is not obvious whether or not net surplus is lower in an underinvestment equilibrium. Clearly, consumers' utility, prior to any redistribution of profits, is lower in an underinvestment equilibrium since consumers value quality. However, firms' profits are unambiguously greater in an underinvestment equilibrium since firms spend less on investment. Indeed, from the viewpoint of a social planner, any investment outlays by a second firm are wasted, holding prices fixed. (A social planner would set price equal to marginal cost, and only one (subsidized) firm would engage in investment and production.)

Nevertheless, the following proposition shows that the welfare comparison is unambiguous. But before stating and proving the proposition, I want to set the problem formally. Given an initial state $\left(u_{-1}^{1}, u_{-1}^{2}\right)$ and any feasible sequence of states, $\left\{\left(u_{t}^{1}, u_{t}^{2}\right)\right\}_{t=0}^{\infty}$, net surplus along this path is equal to

$$
\sum_{t=0}^{\infty} \delta^{t}\left\{\sum_{i=1}^{2} \Pi^{i}\left(u_{t}^{1}, u_{t}^{2}\right)+\sum_{\ell=1}^{N} U^{\ell}\left(u_{t}^{1}, u_{t}^{2}\right)\right\},
$$

where $U^{\ell}(\cdot)$ and $\Pi^{i}(\cdot)$ are given by equations (4) and (5), respectively. (Implicitly, it is assumed here that, in any state, both firms set the stage-2 Nash equilibrium quantities.) Assuming the initial

\footnotetext{
12 The point is the following. If a firm can already serve the whole market with its capacity, any further increase in its capacity has no impact on the firm's market share; this is the exogenous sunk cost case. In contrast, by outspending its rivals in fixed R\&D or advertising outlays, a firm can steal business from its rivals and thus increase its market share, although the investment may not increase industry sales. This is the endogenous sunk cost case.

${ }^{13}$ While important and well founded for investment in quality-improving R\&D, such a normative analysis may not be innocuous in the case of investment in goodwill. 
state satisfies $\left(u_{-1}^{1}, u_{-1}^{2}\right)<(\bar{u}, \bar{u})$, the equilibrium path associated with the noncollusive investment equilibrium $\Sigma^{\text {esc }}$ is $\left(u_{t}^{1}, u_{t}^{2}\right)=(\bar{u}, \bar{u})$ for all $t \geq 0$; in case of underinvestment equilibrium $\Sigma^{\text {coll }}(u)$, it is $\left(u_{t}^{1}, u_{t}^{2}\right)=(u, u)$ for all $t \geq 0$, where by definition of underinvestment, $\max \left\{u_{-1}^{1}, u_{-1}^{2}\right\} \leq u<\bar{u}$.

Proposition 3. In the noncollusive investment equilibrium $\Sigma^{\mathrm{esc}}$ net surplus is higher than in any symmetric underinvestment equilibrium $\Sigma^{\text {coll }}(u)$, where $\max \left\{u_{-1}^{1}, u_{-1}^{2}\right\} \leq u<\bar{u}$.

The intuition behind the result is the following. Even in a second-best world where two firms compete à la Cournot and the quality level is constrained to be identical for both firms, the noncollusive investment equilibrium $\Sigma^{\mathrm{esc}}$ exhibits too low a level of investment; this is true despite the presence of a business stealing effect. The reason is that the duopolists capture only a relatively small part of the surplus from any increase in quality, and thus invest too little. Consequently, the problem of underinvestment is even more severe in any collusive underinvestment equilibrium $\Sigma^{\text {coll }}(u), u<\bar{u}$.

\section{Spillovers and underinvestment}

- So far I have assumed that a firm's investment cost function, $F\left(u_{t}^{i} ; u_{t-1}^{i}\right)$, depends on its own quality level only. However, spillover effects are a pervasive phenomenon in many markets as firms can often cheaply copy their rivals' products. ${ }^{14}$ To highlight the effects of spillovers on the incentives for firms to invest and to collude, I analyze in this section the case where there are no contemporaneous spillovers, but full spillovers after one period.

I now assume that each firm can costlessly "copy" its rival's quality of last period. This means that spillovers are asymmetric in that a low-quality firm benefits from the investment of a high-quality firm, but not vice versa. Formally, the payoff-relevant state at the start of period $t$ is now given by $\left(u_{t-1}^{\max }, u_{t-1}^{\max }\right)$, where $u_{t-1}^{\max } \equiv \max \left\{u_{t-1}^{1}, u_{t-1}^{2}\right\}$, i.e., it lies on the $45^{\circ}$-line in $\left(u^{1}, u^{2}\right)$-space. To shorten notation, denote the state by the scalar $u_{t-1}^{\max }$. Firm $i$ 's investment cost function (2) is now replaced by

$$
F\left(u_{t}^{i} ; u_{t-1}^{\max }\right)=\left(u_{t}^{i}\right)^{\beta}-\left[u_{t-1}^{\max }\right]^{\beta},
$$

where $u_{t}^{i} \geq u_{t-1}^{\max }$.

Intuition may suggest that the presence of spillover effects makes tacit collusion "easier" to sustain (supportable for lower discount factors) since, in the long run, firms will always end up in a symmetric state: by deviating to a high-quality level a firm can no longer ensure itself higher stage-2 profits ad infinitum than in any (symmetric) underinvestment equilibrium. Proposition 4 below shows, however, that this intuition is incorrect; in fact, the opposite result obtains.

I proceed along the lines of my earlier analysis. In the presence of spillovers, firm $i$ 's stationary best reply to $u_{0}^{j}$ is the solution to the following dynamic optimization problem:

$$
\max _{\left\{u_{\tau}^{i} \geq u_{\tau-1}^{\max }\right\}} \sum_{\tau=0}^{\infty} \delta^{\tau} \Pi^{i}\left(u_{\tau}^{1}, u_{\tau}^{2}\right),
$$

where $u_{\tau}^{j}=u_{\tau-1}^{\max }$ for $\tau \geq 1$, and $\Pi^{i}\left(u_{\tau}^{1}, u_{\tau}^{2}\right)=\pi^{i}\left(u_{\tau}^{1}, u_{\tau}^{2}\right)-F\left(u_{\tau}^{i} ; u_{\tau-1}^{\max }\right)$. Firm $i$ 's stationary best reply is then the unique solution to the following program:

$$
\max _{u_{0}^{i} \geq u_{-1}^{\max }} S\left(\frac{u_{0}^{i}}{u_{0}^{i}+u_{0}^{j}}\right)^{2}-\left(u_{0}^{i}\right)^{\beta}+\left[u_{-1}^{\max }\right]^{\beta}+\frac{\delta}{1-\delta} \frac{S}{4},
$$

where the last term is the discounted sum of stage- 2 profits from $\tau=1$ onward that arise when both

\footnotetext{
${ }^{14}$ For a survey on spillovers and R\&D, see de Bondt (1997). See also the literature on R\&D cartels and joint ventures, e.g., d'Aspremont and Jacquemin (1988), Kamien, Muller, and Zang (1992), and Kesteloot and Veugelers (1995). 
firms offer the same qualities. As in the absence of spillovers, one can show that there is a unique intersection of the interior stationary best-reply curves, namely at $(\bar{u}, \bar{u})$, where the symmetric quality level $\bar{u}$ is now given by

$$
\bar{u}=\left(\frac{S}{4 \beta}\right)^{\frac{1}{\beta}} .
$$

Comparing this expression with equation (8), I observe that $\bar{u}$ would assume the same value as in the absence of spillovers if the discount factor were zero.

Since the payoff-relevant state at the start of each period lies on the $45^{\circ}$-line in the state space, I have to modify the definitions of strategy profiles $\Sigma^{\text {esc }}$ and $\Sigma^{\text {coll }}(u)$ accordingly. The noncollusive benchmark strategy profile $\Sigma^{e s c^{\prime}}$ is now induced by the following set of action rules:

(i) If $u_{t-1}^{\max }<\bar{u}$, then $s^{i}\left(u_{t-1}^{\max }\right)=\bar{u}, i=1,2$.

(ii) If $u_{t-1}^{\max } \geq \bar{u}$, then $s^{i}\left(u_{t-1}^{\max }\right)=u_{t-1}^{\max }, i=1,2$.

Analogously to $\Sigma^{\text {coll }}(u)$, the collusive strategy profile $\Sigma^{\text {coll }}(u), u<\bar{u}$, is defined as follows: if $u_{t-1}^{\max } \leq u<\bar{u}$, then $s^{i}\left(u_{t-1}^{\max }\right)=u, i=1,2$; otherwise $s^{i}\left(u_{t-1}^{\max }\right)$ is the same as under $\Sigma^{e s c^{\prime}}$.

I can now state and prove another main result of the article.

Proposition 4. In the presence of spillovers, there exists a unique MPE: the noncollusive investment equilibrium $\Sigma^{e s c^{\prime}}$. Underinvestment cannot be sustained in equilibrium. In particular, the collusive strategy profile $\Sigma^{\text {coll }^{\prime}}(u)$ does not form an MPE.

The intuition for Proposition 4 may be explained as follows. The existence of spillover effects reduces each firm's (noncooperative) incentive to invest, holding fixed its rival's quality. Consequently, the noncollusive investment equilibrium $\Sigma^{e s c^{\prime}}$ exhibits low quality levels in the long run, relative to the investment equilibrium in the absence of spillovers. But any underinvestment equilibrium can only be enforced by the credible threat of escalation. In the presence of spillover effects, however, this threat is rather blunt.

Let me compare the equilibrium investment level when there are spillovers to the investment level when there are no spillovers. Clearly, if firms do not collude in the latter case, then the investment level is higher than in the case with spillovers, holding fixed all parameters. ${ }^{15}$ But if firms do underinvest in the absence of spillovers, then the equilibrium investment level can be higher in the presence of spillovers. To see this, suppose the current state is given by $(u, u)$ and choose parameters such that $\bar{u}>u$ in the presence of spillovers. Then, if the discount factor is sufficiently close to unity, there exists an equilibrium in the absence of spillovers such that no firms raises its quality level above $u$.

To the extent that firms invest in quality-improving R\&D, Proposition 4 has important implications for the literature on patents. A recurrent theme throughout the whole literature is that better patent protection raises firms' incentives to invest in $\mathrm{R} \& \mathrm{D}$, and will hence result in higher equilibrium levels of investment. In a world where technological spillovers are present, one can interpret my model without spillovers as representing the case of infinite patent length, while the extension with spillovers corresponds to the case of short patent length. As I have shown, a shorter patent length can lead to higher equilibrium spending on $\mathrm{R} \& \mathrm{D}$, even though - or rather because-it reduces the incentives to invest, and hence destroys the mechanism through which underinvestment can be supported. In light of the welfare analysis conducted in the last section, this suggests that, for any given discount factor, there exists an "optimal" patent length that gives maximal incentives to invest but is just short enough to prevent firms from colluding in investment. ${ }^{16}$

15 This result on noncollusive investment levels is consistent with many other models of R\&D, where an increase in the level of spillovers reduces each firm's incentive to invest. However, if an increase in own R\&D spending allows a firm to benefit more from its rivals' R\&D efforts, as in the model of “absorptive capacity" by Cohen and Levinthal (1989), then an increase in spillovers may have an additional countervailing effect.

${ }^{16}$ Indeed, suppose there are no spillovers (complete patent protection) for $T$ periods after the investment, and full spillovers (no patent protection) thereafter. It is possible to show that in the limit as $\delta \rightarrow 1$, collusive underinvestment 
Remark. In the limit as the discount factor becomes large, each firm's average payoff in the noncollusive equilibrium approaches the one along an (unsustainable) underinvestment path. To see this, suppose the current state is $(u, u)<(\bar{u}, \bar{u})$. If firms could sustain "no investment" at $(u, u)$, which they cannot even for $\delta$ large, then each firm's average (per-period) payoff would be $S / 4$. In the unique MPE, $\Sigma^{e s c^{\prime}}$, each firm's average payoff is $S / 4-(1-\delta)\left\{\bar{u}^{\beta}-u^{\beta}\right\}$, which converges to $S / 4$ as $\delta \rightarrow 1$. Does this mean that the unsustainability of underinvestment in the presence of spillovers has no important economic implications? The answer is no: even in the limit as $\delta \rightarrow 1$, consumers are (potentially much) better off in state $(\bar{u}, \bar{u})$ than in state $(u, u)<(\bar{u}, \bar{u})$.

\section{Market structure: potential entry}

- Let me now turn to the analysis of market structure by taking up the issue of potential entry that has so far been kept aside in the analysis. The question is whether an underinvestment equilibrium (in which incumbents make large profits) is stable with respect to entry. For this purpose, I extend the basic model by introducing an additional stage in each period at which further entry can occur. The aim is then to investigate whether the incumbents can successfully deter further entry - no matter how large the market-by threatening to engage in an escalation of investment outlays if entry were to occur. This question is of interest for two reasons. First, it relates to the robustness of the two-firm underinvestment equilibrium. Second, it addresses a classic issue in the theory of market structure, namely whether or not concentration can be high in large markets.

The basic model is modified as follows. There are three players: the incumbents, firms 1 and 2 , and a potential entrant, firm 3 . In each period, there are now three stages. At stage 1, the potential entrant decides whether to enter or not if it has not yet decided to do so. If firm 3 decides to enter, it has to pay an entry fee $\varepsilon>0$. At stage 2, the firms that are present in the market (the two incumbents, and firm 3 if it has decided to enter in the current or in an earlier period) decide simultaneously whether and how much to invest in quality improvement. The potential entrant starts up with "zero" quality; its investment cost function in the period of entry is given by $F^{e}(u)=u^{\beta}$, and in all subsequent periods by (2). There are no spillovers. Finally, at stage 3 , firms compete simultaneously in quantities. Consumers' utility is given by the natural extension of (1) to three varieties of the quality good. As before, all past actions are assumed to be common knowledge.

The equilibrium analysis proceeds along the lines of that in Section 3. In period $t$, the state of the industry is given by the quality triple $\left(u_{t}^{1}, u_{t}^{2}, u_{t}^{3}\right)$, where I adopt the convention that $u_{t}^{3}=-1$ if firm 3 has not yet entered the market, and $u_{t}^{3}=0$ if firm 3 has entered the market but not yet invested in quality. A pure-investment action rule is a mapping $s^{i}:\left(u_{t-1}^{1}, u_{t-1}^{2}, u_{t-1}^{3}\right) \mapsto u_{t}^{i}$; a pure output action rule is a mapping $\widetilde{s}^{i}:\left(u_{t}^{1}, u_{t}^{2}, u_{t}^{3}\right) \mapsto x_{t}^{i}$. As before, the minimum quality (necessary to make positive sales) is equal to one; therefore, the initial investment outlays necessary to produce the basic version of the quality good are equal to one.

As to the equilibrium analysis of the output stage, it is straightforward to show that, in any state $\left(u_{t}^{1}, u_{t}^{2}, u_{t}^{3}\right)$, there exists a unique stage-3 Nash equilibrium in pure strategies. If firm 3 has not yet entered the market, or not invested, then its stage- 3 profit is zero, and the incumbents' equilibrium profits are given by (3). Otherwise, firm $i$ 's stage- 3 equilibrium profits are given by

$$
\pi^{i}\left(u_{t}^{1}, u_{t}^{2}, u_{t}^{3}\right)= \begin{cases}S\left(\frac{\sum_{k=1}^{3} u_{t}^{i} / u_{t}^{k}-2}{\sum_{k=1}^{3} u_{t}^{i} / u_{t}^{k}}\right)^{2} & \text { if } \sum_{k=1}^{3} \frac{u_{t}^{\min }}{u_{t}^{k}} \geq 2 \\ S\left(\frac{u_{t}^{i}}{u_{t}^{i}+u_{t}^{j}}\right)^{2} & \text { if } \sum_{k=1}^{3} \frac{u_{t}^{\min }}{u_{t}^{k}}<2 \text { and } u_{t}^{i}, u_{t}^{j}>u_{t}^{\min }(i \neq j) \\ 0 & \text { if } \sum_{k=1}^{3} \frac{u_{t}^{\min }}{u_{t}^{k}}<2 \text { and } u_{t}^{i}=u_{t}^{\min },\end{cases}
$$

cannot be supported for $T$ sufficiently small, but can be supported for $T$ sufficiently large. On the other hand, the noncollusive investment level $\bar{u}$ increases with patent length $T$. 
where $u_{t}^{\min }=\min \left\{u_{t}^{1}, u_{t}^{2}, u_{t}^{3}\right\} \cdot{ }^{17}$ Hence, in the three-firm equilibrium there exists a "quality window" such that a firm makes zero sales if its quality is too low relative to its rivals' qualities. But there will always be at least two firms making positive sales in equilibrium, which explains why there is no quality window in the two-firm case. Observe that $\pi^{i}\left(u_{t}^{1}, u_{t}^{2}, u_{t}^{3}\right)$ is continuous in all its arguments, despite the quality window.

The resulting subgame after entry of firm 3 can, in principle, be analyzed analogously to the two-firm investment game, given the stage-3 profit function (12). However, entry is endogenous and might be deterred by the incumbents. I do not attempt here to investigate the three-firm case comprehensively. Rather, I focus on the question whether or not the two incumbents can be in a two-firm underinvestment equilibrium, and successfully deter entry by credibly threatening to engage in an escalation of investment outlays in case of entry. The following proposition summarizes the results.

Proposition 5. There exists a $\widehat{\beta}>2$ such that if $\beta \in[2, \widehat{\beta}]$, any two-firm underinvestment equilibrium is stable with respect to entry by a third firm. In particular, for $\delta$ sufficiently large, there exists an MPE such that $\left(u_{t}^{1}, u_{t}^{2}, u_{t}^{3}\right)=(u, u,-1)$ for all $t$, and $u \leq \bar{u}$. This is true independently of market size and entry costs.

The proposition shows that the same mechanism that supports underinvestment in equilibrium can be sufficient to deter further entry. It illustrates that concentration can be high even in very large markets. The intuition for this result is closely related to the nonfragmentation result for endogenous sunk cost industries to which I turn in the next section. Before moving on, however, I briefly explain why underinvestment is stable with respect to further entry if $\beta$, the elasticity of the investment cost function, is small $(\beta \leq \widehat{\beta})$ rather than large $(\beta>\widehat{\beta})$. To see this, suppose that if the third firm were to enter the market, the two incumbents would (in the same period) invest up to the symmetric noncollusive quality $\bar{u}$, as given by equation (8), and then cease investing forever. From equation (12), for the entrant to make positive gross profits, it would need to offer a quality of at least $\bar{u} / 2$ (otherwise, consumers would not purchase the good even when offered at marginal cost). But the investment spending necessary to achieve quality $\bar{u} / 2$ is $S[8(1-\delta) \beta]^{-1}$, which is decreasing in $\beta$ (even though an increase in $\beta$ means lower marginal costs of raising quality, holding quality fixed). Intuitively then, if $\beta$ is not too large, the third firm would be unable to recoup its investment outlays.

\section{Market structure: nonfragmentation}

In this section, let me turn to the relationship between market size and concentration when there is free entry. This issue is the subject of Sutton's (1991) work, where he introduces the distinction between "exogenous" and "endogenous sunk cost industries." In exogenous sunk cost industries, where R\&D and advertising do not play an important role, Sutton predicts that the lower bound to concentration converges to zero as market size becomes large. On the other hand, in endogenous sunk cost industries, where R\&D or advertising outlays are significant, the lower bound to concentration is bounded away from zero, no matter how large the market. That is, in contrast to exogenous sunk cost industries, endogenous sunk cost industries cannot become arbitrarily fragmented, not even as market size tends to infinity. ${ }^{18}$

To this date, the nonfragmentation (or nonconvergence) result for endogenous sunk cost industries has been obtained almost solely in static games. ${ }^{19}$ According to Sutton (1998), the open question is whether it still holds in dynamic investment games like mine. In the following, I

\footnotetext{
${ }^{17}$ For a general proof of the $n$-firm case, see the proof of Lemma 4 in the Web Appendix.

${ }^{18}$ For a precise statement of the conditions under which the "nonfragmentation result" for endogenous sunk cost industries holds in static oligopoly models, see Shaked and Sutton (1987) and Sutton (1991). In the case of pure vertical product differentiation and price competition, the finiteness result has been obtained by Shaked and Sutton (1983).

${ }^{19}$ Two exceptions are in Hole (1997) and Sutton (1998). Hole uses the Pakes-McGuire algorithm to simulate a stochastic dynamic model with incremental sunk costs. However, market size (and hence the average number of entrants) is kept small. Sutton analyzes a rather special setting with spillovers, in which the issue of interest-namely the existence of underinvestment equilibria-does not arise.
} 
give three arguments as to why it is not obvious that the nonfragmentation result carries over to my dynamic investment game.

First, suppose that, for any given market size $S$, there exists a symmetric underinvestment equilibrium in which all $n$ active firms offer quality $u$ in each period, where $n$ is such that any additional entrant would make an overall loss. Now, if this underinvestment equilibrium still exists under free entry when the market becomes large, then I am back in an exogenous sunk cost world, in which each firm has to pay an exogenous setup cost of $\varepsilon+F(u)$. Consequently, the nonfragmentation result would break down in this case. (Actually, one could allow quality $u$ to increase with $S$, and still obtain $n \rightarrow \infty$ as $S \rightarrow \infty$, unless $u$ increases too fast with $S$.) Second, in a static game, the nonfragmentation property is proved by showing that in a sufficiently large and fragmented market, there always exists a profitable deviation for some firm. This deviation consists of an escalation of fixed R\&D or advertising outlays so as to capture a larger share of the market. ${ }^{20}$ In a dynamic game, however, such a deviation may not be profitable since it can trigger a future escalation of investment spendings by rival firms, which is detrimental for the deviant firm's profit. Third, and more generally, the nonfragmentation result makes a statement about market structure in any equilibrium of the game. Since the set of equilibria in a dynamic game is much larger, it is not clear whether the same property still holds for all equilibria of the dynamic game. ${ }^{21}$

To address the issue of nonfragmentation, I need to modify the basic version of my dynamic investment game. The time structure is as in Section 6; that is, there are three stages in each period: entry, investment, and quantity competition. There is an initial period (say, 0 ) before which there are no active firms, i.e., all firms are potential entrants in period 0. Entry costs as well as the investment cost functions for a new entrant and for an incumbent are as in Section 6. The consumers' utility function can be generalized in an obvious way to an arbitrary number of firms each offering one variant of the quality good. As before, the output stage in each period can be analyzed as a one-shot game.

Lemma 4. In any state, there exists a unique stage-3 Nash equilibrium in quantities. Suppose there are $n$ active firms. Relabel the firms such that firm 1 offers the highest quality, $u^{1}$, and firm $n$ the lowest quality, $u^{n}$. Then, in equilibrium, there is a quality window such that firms 1 to $\underline{n}$ make only positive sales, where $\underline{n}$ is the maximum integer $z \leq n$, such that $\sum_{i=1}^{z}\left(u^{z} / u^{i}\right)>z-1$. Firm $i$ 's stage- 3 equilibrium profit is given by ${ }^{22}$

$$
\pi^{i}\left(u^{1}, \ldots, u^{i}, \ldots, u^{n}\right)= \begin{cases}S\left(1-\frac{\underline{n}-1}{\sum_{j=1}^{n}\left(u^{i} / u^{j}\right)}\right)^{2} & \text { if } i \leq \underline{n} \\ 0 & \text { otherwise. }\end{cases}
$$

Using equation (13) as the reduced-form stage-3 profit function, I can now focus on the analysis of investment strategies. For technical convenience, restrict attention to equilibria such that all active firms offer the same quality along the equilibrium path, and such that the number of active firms is nondecreasing over time. (In an early version of this article, I showed that the key result of this section is robust to allowing for all asymmetric equilibria in which investment occurs only in the first period; see Nocke, 1998.) Importantly, I allow for all the investment, underinvestment, and entry deterring strategies considered earlier as well as for much more complex strategies.

${ }^{20}$ By offering a (much) higher product than its rivals, a firm can always ensure that it can obtain a larger market share since consumers prefer higher-quality to lower-quality products if offered at the same price. This makes investment in quality different from investment in capacity where a firm that invests in more capacity will not increase its market share unless its capacity constraint was initially binding. Consequently, those industries where capacity investments are important, but R\&D and advertising are not, fall under the heading exogenous sunk cost industries.

${ }^{21}$ The main result of the previous section, Proposition 5, can be seen as an example of nonfragmentation: two firms are able to deter further entry, no matter how large the market, provided $\beta \in[2, \widehat{\beta}]$. However, this equilibrium is not unique; there is another equilibrium in which the two incumbents acquiesce, and further entry takes place.

${ }^{22}$ For notational convenience, I describe the current state by the quality tuple of active firms only. 
In a dynamic game, the lower bound to concentration for a given market size might be quite different from that in a static game. The interesting open question is whether or not the asymptotic properties are the same, namely that the number of active firms remains finite even as market size tends to infinity. In the section on potential entry I have already seen that nonconvergence is a possible outcome in this model; here, I ask whether or not it is a necessary outcome in that it occurs in all equilibria. The following proposition gives the central result on market structure.

Proposition 6 (nonfragmentation). In any MPE, the number of active firms is bounded from above, even as market size tends to infinity.

Proposition 6 is reassuring in that it shows the robustness of the nonfragmentation result to the existence of underinvestment equilibria in dynamic games. It implies that the market share of all firms is bounded away from zero, no matter how large the market. Depending on the discount factor (and other parameters of the model), there may be a plethora of equilibria in the dynamic game. While Proposition 6 shows that the number of active firms is bounded from above in all equilibria, the proposition does not imply that underinvestment equilibria necessarily break down when market size becomes large, as I have already seen in Section 6.

The proof of the nonfragmentation result for the dynamic investment game proceeds by contradiction and may be sketched as follows. Suppose Proposition 6 did not hold and the market became arbitrarily fragmented as market size becomes large. Since firms need to recover their fixed investment outlays, this would imply that firms' investment outlays grow less than proportionately with market size, i.e., $u^{\beta} / S \rightarrow 0$ as $S \rightarrow \infty$. But then a firm might decide to deviate and invest more than its rivals. In particular, if all of its rivals offered quality $u$ (which could depend on market size $S$ ), then a firm might offer, for example, quality $u^{\prime}=[S u]^{1 /(\beta+1)}$. Since $u^{\beta} / S \rightarrow 0$ as $S \rightarrow \infty$, it would follow that $u^{\prime} / u \rightarrow \infty$ as $S \rightarrow \infty$. Moreover, as the market becomes large, the ratio between the deviation profit in the period of deviation and the equilibrium profit in the same period would grow without bound. Hence, even the worst possible punishment that could be inflicted on the deviant firm, namely zero profits in all subsequent periods, would not be sufficient to make this deviation unprofitable. It follows that the number of firms must remain finite.

\section{Conclusion}

- In this article I have explored a dynamic game of investment in quality. It is quite distinct from the industrial organization literature on collusion since here current investments change future market conditions. Since by investing firms can get a persistent lead over their rivals, the existence of tacitly collusive equilibria is no longer trivially ensured. In the first part of the article I focused on the issue of existence of underinvestment equilibria when firms have strong incentives to deviate and, thereby, to persistently improve their strategic position. In the second part, I introduced potential entry into the model so as to address issues of market structure.

Using a state-space approach (and without introducing extraneous state variables summarizing past play), I have shown that collusive underinvestment equilibria can be sustained in the absence of spillovers. In contrast, when there are strong spillovers in the appropriation of the benefits from investment, underinvestment equilibria fail to exist. This implies that a weakening in the degree of patent protection can actually lead to more investment in equilibrium even though (or, rather, because) it reduces the individual incentives to invest. Furthermore, I have shown that underinvestment should be an issue of concern for antitrust authorities in that it unambiguously reduces welfare. This is especially true since detecting tacit collusion in investment levels is likely to be much more difficult than detecting tacit collusion in price or quantity setting.

The existence of underinvestment equilibria has raised the question whether one of the central results on market structure in the IO literature, the nonfragmentation result for endogenous sunk cost industries, breaks down in dynamic investment games. What has been at issue is that, in an underinvestment equilibrium, firms do not engage in an escalation of fixed investment outlays; but without an escalation mechanism at work, the finiteness property cannot hold. My main result on market structure is reassuring: the nonfragmentation result is robust to the existence of underinvestment equilibria. In all equilibria of the dynamic game, industry concentration is bounded away from zero, no matter how large the market.

(c) RAND 2007 


\section{Appendix}

- The proof of Propositions 2, 4, and 6 follow. Proofs of Propositions 3 and 5, and Lemmas 1-4 may be found at www.rje.org/main/sup-matl.html.

Proof of Proposition 2. Since the strategy profile $\Sigma^{\mathrm{esc}}$ forms an MPE, it is sufficient to show that there is no single profitable deviation when the current state is given by $(u, u)$ or $\left(u_{-1}^{1}, u_{-1}^{2}\right)$. Since $s^{i}\left(u_{-1}^{1}, u_{-1}^{2}\right)=u$ and investment costs are additively separable, it is immediate to see that there is no profitable deviation in the initial state $\left(u_{-1}^{1}, u_{-1}^{2}\right)$ if there is no profitable deviation in state $(u, u)$. I can thus confine attention to state $(u, u)$. The proof is organized as follows. I first seek the optimal deviation for any player (due to symmetry, I can confine attention to firm 1), and then show that the associated discounted sum of future profits, $\Pi^{\mathrm{dev}}$, is not larger than the corresponding value in case of nondeviation, $\Pi^{\text {coll }}$. I distinguish three cases.

Case 1. Firm 1, say, deviates in period $t$ by raising its quality to $u^{\prime}$, where $u<u^{\prime}<\bar{u}$; that is, the state moves to $\left(u^{\prime}, u\right)$ in period $t$. According to strategy profile $\Sigma^{\text {coll }}(u)$, both firms will then invest further in period $t+1$, and the state of the industry will be given by $\left(u_{\tau}^{1}, u_{\tau}^{2}\right)=(\bar{u}, \bar{u})$ for all $\tau \geq t+1$. The associated discounted sum of profits for the deviant is equal to

$$
\Pi^{\mathrm{dev}}=S\left(\frac{u^{\prime}}{u^{\prime}+u}\right)^{2}-(1-\delta)\left(u^{\prime}\right)^{\beta}+u^{\beta}+\frac{\delta}{1-\delta} \frac{S}{4}-\delta \bar{u}^{\beta},
$$

while in case of nondeviation it is given by $\Pi^{\text {coll }}=S /[(1-\delta) 4]$. Maximizing $\Pi^{\text {dev }}$ with respect to $u^{\prime}$ gives a first-order condition identical to (8); hence the condition is sufficient for a maximum. Note, however, that the unique positive solution to (8) might be larger than $\bar{u}$. (It is straightforward to show that this is indeed the case when $\bar{u}<(2+\sqrt{5}) u$; I am dealing with this case in part (ii) of the proof. Hence, in the following I analyze the case when the reverse inequality holds. By choosing $\delta$ sufficiently close to 1 this can always be ensured.) Denote the optimal value of $u^{\prime}$ by $u^{\prime}(u)$. Then, from (8), $(1-\delta)\left[u^{\prime}(u)\right]^{\beta}=(2 / \beta) S\left[u^{\prime}(u)\right]^{2} u /\left[u^{\prime}(u)+u\right]^{3}$. Substituting $(1-\delta)\left[u^{\prime}(u)\right]^{\beta}$ and $\bar{u}$ in (A1) gives

$$
\Pi^{\mathrm{dev}}=S\left(\frac{u^{\prime}(u)}{u^{\prime}(u)+u}\right)^{2}-\frac{2 S\left[u^{\prime}(u)\right]^{2} u}{\beta\left[u^{\prime}(u)+u\right]^{3}}+u^{\beta}+\frac{\delta}{1-\delta} \frac{S}{4}\left(\frac{\beta-1}{\beta}\right),
$$

which is continuous in $\delta$. Now, multiplying both sides by $(1-\delta)$, and taking the limit as $\delta$ goes to one, one gets

$$
\lim _{\delta \rightarrow 1}(1-\delta) \Pi^{\mathrm{dev}}=\frac{S}{4}\left(\frac{\beta-1}{\beta}\right)<\frac{S}{4}=\lim _{\delta \rightarrow 1}(1-\delta) \Pi^{\text {coll }} .
$$

Hence, there exists a $\widehat{\delta}^{(i)}<1$ such that for all $\delta \geq \widehat{\delta}^{(i)}$ deviation is not profitable.

Case 2. Suppose now that, in period $t$, firm 1 deviates to a quality $u^{\prime}$ such that $\widehat{u}^{-1}(u)>u^{\prime} \geq \bar{u}$. In period $t+1$, firm 2 will then react and raise its quality to $\widehat{u}\left(u^{\prime}\right)$, where $u<\widehat{u}\left(u^{\prime}\right) \leq \bar{u}$. Hence, the sequence of states induced by the deviation will be given by $\left(u_{\tau}^{1}, u_{\tau}^{2}\right)=\left(u^{\prime}, u\right)$ for $\tau=t$, and $\left(u_{\tau}^{1}, u_{\tau}^{2}\right)=\left(u^{\prime}, \widehat{u}\left(u^{\prime}\right)\right)$ for $\tau \geq t+1$. The deviant's discounted sum of profits is thus equal to

$$
\Pi^{\mathrm{dev}}=S\left(\frac{u^{\prime}}{u^{\prime}+u}\right)^{2}-\left(u^{\prime}\right)^{\beta}+u^{\beta}+\frac{\delta}{1-\delta} S\left(\frac{u^{\prime} / \widehat{u}\left(u^{\prime}\right)}{u^{\prime} / \widehat{u}\left(u^{\prime}\right)+1}\right)^{2} .
$$

Maximizing this expression with respect to $u^{\prime}$ yields the first-order condition for optimal deviation

$$
2 S \frac{u^{\prime} u}{\left[u^{\prime}+u\right]^{3}}-\beta\left(u^{\prime}\right)^{\beta-1}+2 S \frac{\delta}{1-\delta} \frac{u^{\prime}\left[\widehat{u}\left(u^{\prime}\right)-u^{\prime} \frac{d \widehat{u}\left(u^{\prime}\right)}{d u^{\prime}}\right]}{\left[u^{\prime}+\widehat{u}\left(u^{\prime}\right)\right]^{3}}=0,
$$

where $\widehat{u}\left(u^{\prime}\right)$ is implicitly defined by $(8)$, and $d \widehat{u}\left(u^{\prime}\right) / d u^{\prime}$ can be obtained by implicit differentiation of (8):

$$
\frac{d \widehat{u}\left(u^{\prime}\right)}{d u^{\prime}}=-\frac{\frac{2 S}{1-\delta} \frac{\widehat{u}\left(u^{\prime}\right)\left[\widehat{u}\left(u^{\prime}\right)-2 u^{\prime}\right]}{\left[u^{\prime}+\widehat{u}\left(u^{\prime}\right)\right]^{4}}}{\frac{2 S}{1-\delta} \frac{u^{\prime}\left[u^{\prime}-2 \widehat{u}\left(u^{\prime}\right)\right]}{\left[u^{\prime}+\widehat{u}\left(u^{\prime}\right)\right]^{4}}-\beta(\beta-1)\left[\widehat{u}\left(u^{\prime}\right)\right]^{\beta-2}} .
$$

In order to reduce the dimensionality of the problem, let me define $u_{\lambda}^{\prime}$ such that $\widehat{u}\left(u_{\lambda}^{\prime}\right)=\lambda u_{\lambda}^{\prime}$, where $\lambda \in(0,1]$. For a fixed $\lambda$, the first-order condition for the nondeviant's best reply to $u_{\lambda}^{\prime},(8)$, can then be rewritten as

$$
\frac{2 S}{1-\delta} \frac{u_{\lambda}^{\prime}\left(\lambda u_{\lambda}^{\prime}\right)}{\left[u_{\lambda}^{\prime}+\lambda u_{\lambda}^{\prime}\right]^{3}}-\beta\left[\lambda u_{\lambda}^{\prime}\right]^{\beta-1}=0
$$


Solving for $u_{\lambda}^{\prime}$ gives

$$
u_{\lambda}^{\prime}=\left(\frac{2 S}{(1-\delta) \beta} \frac{1}{\lambda^{\beta-2}(1+\lambda)^{3}}\right)^{1 / \beta} .
$$

This enables me to calculate $d \widehat{u}\left(u^{\prime}\right) / d u^{\prime}$ locally at $u^{\prime}=u_{\lambda}^{\prime}$, as a function of $\lambda$ :

$$
\left.\frac{d \widehat{u}\left(u^{\prime}\right)}{d u^{\prime}}\right|_{u^{\prime}=u_{\lambda}^{\prime}}=-\frac{\lambda(2-\lambda)}{2 \lambda-1+(\beta-1)(1+\lambda)},
$$

which is strictly negative for $\lambda \in(0,1]$ and $\beta \geq 2$ : the higher is the deviant's quality, the less will be invested by its rival.

I can interpret firm 1's optimal deviation problem as a choice of $\lambda$. The deviant's first-order condition, (A3), for the optimal $\lambda$, denoted by $\lambda_{\delta}$, can now be written as

$$
2 S \frac{u_{\lambda_{\delta}}^{\prime} u}{\left[u_{\lambda_{\delta}}^{\prime}+u\right]^{3}}-\beta\left(u_{\lambda_{\delta}}^{\prime}\right)^{\beta-1}+2 S \frac{\delta}{1-\delta} \frac{u_{\lambda_{\delta}}^{\prime}\left[\lambda_{\delta} u_{\lambda_{\delta}}^{\prime}-\left.u_{\lambda_{\delta}}^{\prime} \frac{d \widehat{u}\left(u^{\prime}\right)}{d u^{\prime}}\right|_{u^{\prime}=u_{\lambda_{\delta}}^{\prime}}\right]}{\left[\lambda_{\delta} u_{\lambda_{\delta}}^{\prime}+u_{\lambda_{\delta}}^{\prime}\right]^{3}}=0,
$$

where $u_{\lambda_{\delta}}^{\prime}$ and $d \widehat{u}\left(u^{\prime}\right) /\left.d u^{\prime}\right|_{u^{\prime}=u_{\lambda_{\delta}}^{\prime}}$ are given by (A4) and (A5), respectively. Multiplying both sides by $(1-\delta)$, taking the limit as $\delta$ goes to one, and simplifying, one gets

$$
\xi\left(\lambda_{1}\right) \equiv \lambda_{1}^{\beta}+\lambda_{1}^{\beta-1}-\frac{1+\beta}{\beta} \lambda_{1}-\frac{\beta-2}{\beta}=0,
$$

where $\lambda_{1}=\lim _{\delta \rightarrow 1} \lambda_{\delta}$. This is the first-order condition for the optimal $\lambda$ as a function of $\beta$ in the limit when $\delta \rightarrow 1$. Since the sign of the coefficients in (A6) changes once if $\beta \geq 2$, Descartes' sign rule tells me that (A6) has exactly one (strictly) positive root. ${ }^{23}$ Now, $\xi(1)=1 / \beta, \xi(0)=(2-\beta) / \beta \leq 0$ if $\beta \geq 2$, and $\xi^{\prime}(0)<0$. Hence, if $\beta \geq 2$, there exists exactly one $\lambda_{1} \in(0,1]$ such that $\xi\left(\lambda_{1}\right)=0$. Since an increase in $u^{\prime}$ corresponds to a decrease in $\lambda$, and $\xi(0) \leq 0$ and $\xi(1)>0$, (A6) defines indeed a maximum! The optimal choice of $\lambda$, in the limit when $\delta \rightarrow 1$, is therefore the unique $\lambda_{1} \in(0,1]$ satisfying (A6). ${ }^{24}$ It is straightforward to show that $\lambda_{1}$ is strictly increasing in $\beta,{ }^{25}$ and that $\lambda_{1} \rightarrow 1$ as $\beta \rightarrow \infty .{ }^{26}$.

Substituting $u^{\prime}$ in (A2) by $u_{\lambda_{1}}^{\prime}$, as given by (A4), and substituting $\widehat{u}\left(u^{\prime}\right)$ by $\lambda_{1} u_{\lambda_{1}}^{\prime}$, multiplying both sides of (A2) by $(1-\delta)$, and taking the limit as $\delta \rightarrow 1$, yields

$$
\begin{aligned}
\lim _{\delta \rightarrow 1}(1-\delta) \Pi^{\mathrm{dev}} & =\frac{S}{\left(1+\lambda_{1}\right)^{2}}\left(1-\frac{2}{\beta \lambda_{1}^{\beta-2}\left(1+\lambda_{1}\right)}\right) \\
& =\frac{S}{\left(1+\lambda_{1}\right)^{2}}\left(1-\frac{2}{\beta+1+(\beta-2) / \lambda_{1}}\right) \\
& =\frac{S}{\left(1+\lambda_{1}\right)^{2}}\left(\frac{(\beta-1) \lambda_{1}+\beta-2}{(\beta+1) \lambda_{1}+\beta-2}\right) \equiv \widehat{\Pi}^{\mathrm{dev}}\left(\lambda_{1}, \beta\right),
\end{aligned}
$$

where the second equality follows from the definition of $\lambda_{1}$ in equation (A6). Observe that $2 \widehat{\Pi}^{\operatorname{dev}}\left(\lambda_{1}, \beta\right) / \partial \lambda_{1}<0$. To find a suitable lower bound on $\lambda_{1}$, let me define

$$
\eta(\lambda) \equiv \lambda^{2}-\frac{\lambda}{\beta(\beta-1)}-\frac{\beta-2}{\beta} .
$$

\footnotetext{
${ }^{23}$ It is straightforward to generalize Descartes' sign rule, which has been developed for polynomials, to the case when the powers are not necessarily integers, but (more generally) rational numbers. To see this, define $\xi(x) \equiv a_{0}+$ $a_{1} x^{b_{1}}+\cdots+a_{n} x^{b_{n}}$, where $b_{i}=p_{i} / q_{i}$ and $p_{i}, q_{i} \in N$. Suppose $q$ is the smallest common denominator of the $b_{i}$ 's. Then, $\xi(x)$ can be rewritten as a polynomial: $\xi(x)=a_{0}+a_{1} y^{\widetilde{b}_{1}}+\cdots+a_{n} y^{\widetilde{b}_{n}}$, where $y \equiv x^{1 / q}$ and $\widetilde{b}_{i} \equiv q p_{i} / q_{i} \in N$. As to irrational $\beta$ 's, one can show that, in this case, $\xi(x)$ has exactly one sign change at some positive $x$ for any real (rational or irrational) $\beta \geq 2$.

${ }^{24}$ Here, I abstract from the lower bound on $\lambda_{1}$, which is given by $u / \widehat{u}^{-1}(u)$.

${ }^{25}$ Implicit differentiation of (A6) gives $d \lambda_{1} / d \beta=-\left[\left(\ln \lambda_{1}\right)\left(\lambda_{1}^{\beta}+\lambda_{1}^{\beta-1}\right)+\left(\lambda_{1}-2\right) / \beta^{2}\right] /\left[\beta \lambda_{1}^{\beta-1}+(\beta-1) \lambda_{1}^{\beta-2}-\right.$ $(\beta+1) / \beta$ ]. Clearly, the numerator of the right-hand-side expression is negative for $\lambda_{1} \leq 1$. As to the denominator, (A6) implies that $\lambda_{1}^{\beta}+\lambda_{1}^{\beta-1}-(1+\beta) \lambda_{1} / \beta=(\beta-2) / \beta \geq 0$ if $\beta \geq 2$, and hence $\beta \lambda_{1}^{\beta-1}+(\beta-1) \lambda_{1}^{\beta-2}-(1+\beta) / \beta>$ $\lambda_{1}^{\beta-1}+\lambda_{1}^{\beta-2}-(1+\beta) / \beta \geq 0$ if $\beta \geq 2$. That is, the denominator is positive, and hence $d \lambda_{1} / d \beta>0$, for $\beta \geq 2$.

${ }^{26}$ To see this, suppose otherwise that $\lambda_{1} \rightarrow k<1$ as $\beta \rightarrow \infty$. Then, from (A6), it follows that $\xi\left(\lambda_{1}\right) \rightarrow-k-1<0$ as $\beta \rightarrow \infty$. But this contradicts the definition of $\lambda_{1}$.

(c) RAND 2007 .
} 
If $\beta \geq 2$, there is a unique strictly positive $\widehat{\lambda}_{1}$ such that $\eta\left(\widehat{\lambda}_{1}\right)=0$; it is given by $\widehat{\lambda}_{1}=(\beta-1) / \beta$. Furthermore, I have $\eta(\lambda) \geq \xi(\lambda)$ for all $\lambda \in(0,1]$, where $\xi(\lambda)$ is defined as in (A6). Hence, $\widehat{\lambda}_{1} \leq \lambda_{1}$ and $\widehat{\Pi}^{\operatorname{dev}}\left(\widehat{\lambda}_{1}, \beta\right) \geq \widehat{\Pi}^{\operatorname{dev}}\left(\lambda_{1}, \beta\right)=$ $\lim _{\delta \rightarrow 1}(1-\delta) \Pi^{\mathrm{dev}}$.

Remark that if $\beta=2$, then $\widehat{\lambda}_{1}=1 / 2$, and $\widehat{\Pi}^{\operatorname{dev}}(1 / 2,2)=4 S / 27<S / 4=\lim _{\delta \rightarrow 1}(1-\delta) \Pi^{\text {coll }}$. One can show that the total derivative of $\widehat{\Pi}^{\operatorname{dev}}\left(\widehat{\lambda}_{1}(\beta), \beta\right)$ with respect to $\beta$ is positive: the higher is the elasticity of the investment cost function, the higher is the upper bound on the profits from deviation. Finally note that $\widehat{\lambda}_{1}(\beta) \rightarrow 1$ as $\beta \rightarrow \infty$, and thus $\widehat{\Pi}^{\operatorname{dev}}\left(\widehat{\lambda}_{1}(\beta), \beta\right) \rightarrow \beta \rightarrow \infty S / 4=\lim _{\delta \rightarrow 1}(1-\delta) \Pi^{\text {coll }}$. Hence, for all $\beta \geq 2, \lim _{\delta \rightarrow 1}(1-\delta) \Pi^{\operatorname{dev}}<\lim _{\delta \rightarrow 1}(1-\delta) \Pi^{\text {coll }}$

Because of continuity in $\delta$, there exists therefore, for any $\beta \geq 2$, a threshold value $\widehat{\delta}^{(i i)}<1$ such that for all $\delta \geq \widehat{\delta}^{(i i)}$, deviation is not profitable.

Case 3. Finally, suppose the deviant firm (firm 1, say) preempts any reaction by its rival. That is, in period $t$, firm 1 chooses a quality level $u^{\prime}$ such that $\widehat{u}\left(u^{\prime}\right) \leq u$; in the induced subgame, the state of the industry will then be given by $\left(u_{\tau}^{1}, u_{\tau}^{2}\right)=\left(u^{\prime}, u\right)$ for all $\tau \geq t$.

Since $\widehat{u}^{-1}(u)>\widehat{u}(u)$ (where the inverse of $\widehat{u}(\cdot)$ is defined over the decreasing part of $\widehat{u}(\cdot)$ only), the deviant firm chooses $u^{\prime}$ such that $\widehat{u}\left(u^{\prime}\right)=u$ so that its rival is just preempted. That is, the optimal preemptive deviation, $u^{\prime}$, is implicitly defined by

$$
\phi\left(u^{\prime}\right) \equiv \frac{2 S}{1-\delta} \frac{u u^{\prime}}{\left(u+u^{\prime}\right)^{3}}-\beta u^{\beta-1}=0 .
$$

Now, $\phi(u)>0$ if and only if $u<\bar{u}$ (which is, of course, the relevant case of underinvestment, and can always be ensured by choosing $\delta$ sufficiently large), $\lim _{u^{\prime} \rightarrow \infty} \phi\left(u^{\prime}\right)=-\beta u^{\beta-1}<0$, and $\phi^{\prime}\left(u^{\prime}\right)<0$ for all $u^{\prime}>u / 2$. Thus, if $u<\bar{u}$, there exists a unique $u^{\prime}, u^{\prime}>u$, such that $\phi\left(u^{\prime}\right)=0$. Define $\psi\left(u^{\prime}\right) \equiv u^{\prime} /\left(u+u^{\prime}\right)$, and note that $\psi\left(u^{\prime}\right) \in(1 / 2,1)$, and $\lim _{u^{\prime} \rightarrow \infty} \psi\left(u^{\prime}\right)=1$. Equation (A7) can now be rewritten, and solved for $u^{\prime}$ :

$$
u^{\prime}=\left(\frac{2 S}{(1-\delta) \beta} \frac{\psi\left(u^{\prime}\right)}{u^{\beta-2}}\right)^{1 / 2}-u
$$

The discounted sum of profits from deviation is then equal to

$$
\Pi^{\operatorname{dev}}=\frac{S}{(1-\delta)}\left[\frac{\left(\frac{2 S}{(1-\delta) \beta} \frac{\psi\left(u^{\prime}\right)}{u^{\beta-2}}\right)^{1 / 2}-u}{\left(\frac{2 S}{(1-\delta) \beta} \frac{\psi\left(u^{\prime}\right)}{u^{\beta-2}}\right)^{1 / 2}}\right]^{2}-\left[\left(\frac{2 S}{(1-\delta) \beta} \frac{\psi\left(u^{\prime}\right)}{u^{\beta-2}}\right)^{1 / 2}-u\right]^{\beta}+u^{\beta},
$$

and, hence,

$$
\lim _{\delta \rightarrow 1}(1-\delta) \Pi^{\operatorname{dev}}= \begin{cases}-\infty & \text { if } \beta>2 \\ 0 & \text { if } \beta=2 \\ S & \text { otherwise. }\end{cases}
$$

Since $\beta \geq 2$, there exists therefore a $\widehat{\delta}^{(i i i)}<1$ such that for all $\delta \geq \widehat{\delta}^{(i i i)}, \Pi^{\text {dev }}<\Pi^{\text {coll }}$. $\quad$ Q.E.D.

A dynamic model of investment in capacity. I briefly sketch a dynamic game of investment in capacity to illustrate the remark in Section 3. There are two firms, indexed by $i \in\{1,2\}$, which produce a homogeneous good. Time is discrete; firms have an infinite horizon, and employ a common discount factor $\delta$. In each period, market demand for the homogeneous good is $D(p)=S(1-p)$, where $p$ is price and $S$ market size. Timing in each period is as follows. At the first stage, the two firms simultaneously decide how much to invest in capacity. Given current capacity $k_{-1}^{i}$, firm $i$ 's cost of reaching capacity level $k^{i} \geq k_{-1}^{i}$ is given by $F\left(k^{i} ; k_{-1}^{i}\right)$. I assume that $F$ is weakly increasing in its first argument and weakly decreasing in its second argument. Capacity does not depreciate, and so $k_{t}^{i} \geq k_{t-1}^{i}$ in every period $t$. At the second stage, the two firms simultaneously decide how much output to produce. Each firm $i$ 's output choice $q^{i}$ is subject to the capacity constraint $q^{i} \leq k^{i}$. The marginal cost of output is zero. However, in each period, a firm has to incur a maintenance cost $c$ per unit of current capacity. Following Fudenberg and Tirole (1983), I assume that $c$ is sufficiently large so that for the relevant range of capacity levels, each firm $i$ optimally dumps its whole capacity on the market, $q^{i}=k^{i}$. That is, firm $i$ 's stage- 2 equilibrium profit function is $\pi^{i}\left(k^{1}, k^{2}\right)=S k^{i}\left(1-c-k^{1}-k^{2}\right)$.

Firm $i$ 's stationary best reply to capacity level $k^{j}$ is the solution to the following program:

$$
\max _{k^{i} \geq k_{-1}^{i}} S k^{i}\left(1-c-k^{1}-k^{2}\right)-(1-\delta) F\left(k^{i} ; k_{-1}^{i}\right)
$$

Since a firm has no incentive to build more capacity than is necessary to serve market demand at a price equal to marginal cost, the solution satisfies $k^{i} \leq 1-c$ (provided $k_{-1}^{i} \leq 1-c$ ). Since the upper bound on capacity investment is independent of the discount factor, investment costs are bounded from above. Hence, in the limit as $\delta \rightarrow 1$, firm $i$ 's interior stationary 
best reply to $k^{j}, \widehat{k}\left(k^{j}\right)$, is the solution to

$$
\max _{k^{i} \geq k_{-1}^{i}} S k^{i}\left(1-c-k^{1}-k^{2}\right),
$$

and so

$$
\widehat{k}\left(k^{j}\right)=\frac{1-c-k^{j}}{2} .
$$

The unique intersection of these limiting reaction curves is given by

$$
(\bar{k}, \bar{k})=\left(\frac{1-c}{3}, \frac{1-c}{3}\right) .
$$

For $\delta=1$, the noncollusive and collusive strategy profiles, $\Sigma^{\mathrm{esc}}$ and $\Sigma^{\mathrm{coll}}(k)$, can then be defined in the same way as in the dynamic game of investment in quality.

Note that there is a subtle but important difference between investment in capacity and investment in quality when the discount factor becomes large. In the capacity investment model, the interior stationary reaction curves converge to some limiting curves as $\delta \rightarrow 1$. In contrast, in the quality investment game, the stationary reaction curves do not converge to some limiting curves: in the case of investment in quality, each firm always has an incentive to offer a higher quality than its rival, no matter how large the quality of its rival, and this incentive is increasing with the magnitude of the discount factor. This difference gives rise to the following result.

Claim A1. For $\delta$ sufficiently large, underinvestment at any state $(k, k)<((1-c) / 4,(1-c) / 4)$ cannot be sustained as an equilibrium outcome by the collusive strategy profile $\Sigma^{\text {coll }}(k)$.

Proof. Suppose the assertion is false. Then, there exists some $k<(1-c) / 4$ such that $\Sigma^{\text {coll }}(k)$ forms an MPE. Since I am interested in the limit as $\delta \rightarrow 1$, I define a firm's average payoff as the firm's discounted sum of future profits multiplied by $(1-\delta)$. Consider now firm 1 , say. If it does not deviate in state $(k, k)$, its average payoff along the candidate equilibrium path is $S k(1-c-2 k)$. Suppose now that firm 1 deviates to $k^{\prime}=(1-c) / 2>k$. In the limit as $\delta \rightarrow 1$, the state of the industry will-in the period following the deviation-move to $\left(k^{\prime}, \widehat{k}\left(k^{\prime}\right)\right)=((1-c) / 2,(1-c) / 4)$, and stay there forever. Hence, as $\delta \rightarrow 1$, firm 1's average payoff from deviating becomes

$$
S k^{\prime}\left(1-c-k^{\prime}-\widehat{k}\left(k^{\prime}\right)\right)=S \frac{(1-c)^{2}}{8},
$$

which is larger than $S k(1-c-2 k)$ if and only if $k<(1-c) / 4$. Hence, for $\delta$ sufficiently large, the collusive strategy profile $\Sigma^{\text {coll }}(k), k<(1-c) / 4$, does not form an MPE. Q.E.D.

Proof of Proposition 4. The proof proceeds in several steps.

(i) Suppose the current state, $u_{-1}^{\max }$, is above $\bar{u}$, i.e. $u_{-1}^{\max } \geq \bar{u}$. Then, at most one firm will invest along the equilibrium path in any given period. To prove this claim, I consider period $t$, and assume that $u_{t}^{j} \leq u_{t}^{i}=u_{t}^{\max }$ along the equilibrium path. It is easy to see that it is optimal for firm $j$ to set $u_{t}^{j}=u_{t-1}^{\max }$ : the choice of $u_{t}^{j}$ does not affect $j$ 's payoff in the continuation game as long as $u_{t}^{j} \leq u_{t}^{i}$, and firm $j$ 's best reply from below to $u_{t}^{\max }$ is given by the solution to

$$
\max _{u_{t}^{j} \in\left[u_{t-1}^{\max }, u_{t}^{i}\right]} S\left(\frac{u_{t}^{j}}{u_{t}^{j}+u_{t}^{i}}\right)^{2}-\left(u_{t}^{j}\right)^{\beta}+\left(u_{t-1}^{\max }\right)^{\beta},
$$

which is equal to $u_{t-1}^{\max }$ since $u_{t-1}^{\max } \geq \bar{u}$.

(ii) I now claim that no firm will invest along the equilibrium path starting from any state $u_{-1}^{\max }$ above $\bar{u}$. To see this, suppose otherwise. From (i), I know that at most one firm invests in any given period. Assume firm $i$ invests in period $t$ (and hence firm $j$ does not), and let $V^{i}(\cdot)$ denote firm $i$ 's value function. Then, firm $i$ 's discounted sum of profits (or value) in period $t, V^{i}\left(u_{t-1}^{\max }\right)$, must satisfy

$$
\begin{aligned}
V^{i}\left(u_{t-1}^{\max }\right) & =\max _{u \geq u_{t-1}^{\max }} S\left(\frac{u}{u+u_{t-1}^{\max }}\right)^{2}-u^{\beta}+\left(u_{t-1}^{\max }\right)^{\beta}+\delta V^{i}(u) \\
& \geq S / 4+\delta V^{i}\left(u_{t-1}^{\max }\right),
\end{aligned}
$$

where the inequality follows from the fact that $i$ may decide not to invest, in which case $u_{t}^{\max }=u_{t-1}^{\max }$. This yields

(c) RAND 2007

$$
V^{i}\left(u_{t-1}^{\max }\right) \geq \frac{S}{4(1-\delta)} .
$$


Since each firm's gross profit is decreasing in its rival's quality, I obtain an upper bound on firm $i$ 's profit by assuming that firm $j$ will never invest again in the future. Firm $i$ 's stationary best reply to any quality level above $\bar{u}$ is never to invest. Hence, for any $u \geq \bar{u}$,

$$
V^{i}(u) \leq \frac{S}{4(1-\delta)} .
$$

Combining the equations gives $V^{i}\left(u_{t-1}^{\max }\right)=S /[4(1-\delta)], i=1,2$, and $u_{t}^{\max }=u_{t-1}^{\max }$.

(iii) Suppose now that $u_{t-1}^{\max } \leq \bar{u}$. I claim that $u_{t}^{\max } \leq \bar{u}$. To see this, suppose $u_{t}^{\max } \geq \bar{u}$ so that the continuation payoff for both firms is given by $V^{i}\left(u_{t}^{\max }\right)=S /[4(1-\delta)], i=1,2$. Assume $\bar{u} \leq u_{t}^{1}=u_{t}^{\max }$. Then the two value functions must satisfy

$$
V^{1}\left(u_{t-1}^{\max }\right)=\max _{u^{1} \geq \bar{u}} S\left(\frac{u_{t}^{1}}{u_{t}^{2}+u_{t}^{1}}\right)^{2}-\left(u_{t}^{1}\right)^{\beta}+\left(u_{t-1}^{\max }\right)^{\beta}+\delta \frac{S}{4(1-\delta)},
$$

and

$$
V^{2}\left(u_{t-1}^{\max }\right)=\max _{u^{2} \geq u_{t-1}^{\max }} S\left(\frac{u_{t}^{i}}{u_{t}^{j}+u_{t}^{i}}\right)^{2}-\left(u_{t}^{j}\right)^{\beta}+\left(u_{t-1}^{\max }\right)^{\beta}+\delta \frac{S}{4(1-\delta)} .
$$

The only tuple $\left(u_{t}^{1}, u_{t}^{2}\right)$ that satisfies both equations is given by $(\bar{u}, \bar{u})$. Hence, $u_{t-1}^{\max } \leq \bar{u}$ implies $u_{t}^{\max } \in\left[u_{t-1}^{\max }, \bar{u}\right]$.

(iv) Any equilibrium is symmetric. That is, along the equilibrium path, $u_{t}^{1}=u_{t}^{2}=u_{t}^{\max }$ for all $t$. Above, I have shown that this holds for the unique equilibrium starting from state $u_{-1}^{\max } \geq \bar{u}$. I now extend this result to the case where $u_{-1}^{\max } \leq \bar{u}$. From my earlier analysis, I know that $u_{t}^{\max } \in\left[u_{t-1}^{\max }, \bar{u}\right]$ for all $t$. I claim that firm $i$ has a profitable deviation if $u_{t}^{i}<u_{t}^{j}=u_{t}^{\max }$. Indeed, firm $i$ 's quality choice does not affect its continuation payoff provided that it does not invest more than its rival. But firm $i$ 's best reply from below is to set its quality equal to the rival's quality since $\widehat{u}(u) \geq u$ for any $u \leq \bar{u}$.

(v) Suppose that $u_{t-1}^{\max } \leq \bar{u}$ and $\widehat{u}\left(u_{t-1}^{\max }\right) \geq \bar{u}$. I then claim that $u_{s}^{1}=u_{s}^{2}=\bar{u}$ for all $s \geq t$. To see this, recall again that I obtain an upper bound on firm $i$ 's profit by assuming that firm $j$ will never invest again in the future. Now, if $u_{s}^{j}<\bar{u}$, then firm $i$ may deviate to $\widehat{u}\left(u_{s}^{j}\right) \geq \bar{u}$. In the equilibrium of the induced subgame, both firms will never invest again. By definition of $\widehat{u}(\cdot)$, the deviation must therefore be profitable.

(vi) Suppose that $u_{t-1}^{\max } \leq \bar{u}$ and $\widehat{u}\left(u_{t-1}^{\max }\right) \leq \bar{u}$. Note that the latter inequality holds if and only if $\bar{u} \geq(2+\sqrt{5}) u_{t-1}^{\max }$. I now prove by contradiction that $u_{s}^{1}=u_{s}^{2}=\bar{u}$ for all $s \geq t$. Assume to the contrary that $u_{t}^{\max }<\bar{u}$ and consider a period- $t$ deviation by firm 1 to quality level $\bar{u}$. The deviation induces the following sequence of quality levels: $\left(u_{t}^{1}, u_{t}^{2}\right)=(\bar{u}, u)$, and $\left(u_{s}^{1}, u_{s}^{2}\right)=(\bar{u}, \bar{u})$ for all $s \geq t+1$. The deviation is profitable if and only if

$$
\begin{gathered}
S\left(\frac{\bar{u} / u_{t}^{\max }}{1+\bar{u} / u_{t}^{\max }}\right)^{2}-\bar{u}^{\beta}+\left(u_{t}^{\max }\right)^{\beta}+\frac{\delta}{1-\delta} \frac{S}{4}>\frac{1}{1-\delta} \frac{S}{4} \\
\Leftrightarrow S\left(\frac{\bar{u} / u_{t}^{\max }}{1+\bar{u} / u_{t}^{\max }}\right)^{2}>\frac{S}{4}\left(\frac{\beta+1}{\beta}\right)-\left(u_{t}^{\max }\right)^{\beta} \\
\Leftarrow \beta>\left[4\left(\frac{\bar{u} / u_{t}^{\max }}{1+\bar{u} / u_{t}^{\max }}\right)^{2}-1\right]^{-1} .
\end{gathered}
$$

For a given $\beta$, the left-hand side of the last inequality is independent of $u_{t}^{\max }$ and $\bar{u}$, while the right-hand side is strictly decreasing in the ratio $\bar{u} / u_{t}^{\max }$, for $\bar{u} \geq u_{t}^{\max }$. Since $\bar{u} \geq(2+\sqrt{5}) u_{t}^{\max }$, the proof is complete if one can show that

$$
\beta>\left[4\left(\frac{2+\sqrt{5}}{1+2+\sqrt{5}}\right)^{2}-1\right]^{-1}=0.61803
$$

But this inequality holds by assumption. Q.E.D.

Proof of Proposition 6. As mentioned in the main text, for simplicity restrict attention to equilibria in which the number of active firms, $n_{t}$, is nondecreasing over time, $n_{t} \geq n_{t-1}$ for all $t \geq 0$, and in which, in each period $t$, all active firms offer the same quality, $u_{t}$. I will show by contradiction that there exists a finite bound $\bar{n}$ on the number of active firms, $n_{t} \leq \bar{n}$ for all $t \geq 0$. This bound $\bar{n}$ is independent of market size. Since $n_{t}$ is trivially bounded for any given market size $S$, I will consider the limit as $S \rightarrow \infty$.

Consider an arbitrary date $\widehat{t}$ at which entry occurs (i.e., such that $n_{\widehat{t}}>n_{\widehat{t}-1}$ ); since the market opens in period 0 , such a date must exist. A new entrant's discounted sum of profits along the equilibrium path is bounded from above by

$$
\frac{S}{(1-\delta) n_{\widehat{t}}^{2}}-u_{\widehat{t}}^{\beta}-\varepsilon
$$


since the entrant's discounted sum of profits are maximized if no future entry and no future investment occurs. In equilibrium, the entrant's discounted sum of profits must be nonnegative, which requires that

$$
\frac{1}{(1-\delta) n_{\hat{t}}^{2}} \geq\left(\frac{u_{\hat{t}}^{\beta}}{S}\right)+\frac{\varepsilon}{S}
$$

Suppose now that, in period $\widehat{t}$, either a new entrant or an incumbent firm deviates by investing up to quality level

$$
u^{\prime}=\left[S u_{t}\right]^{1 /(\beta+1)},
$$

where $u^{\prime}>u_{\hat{t}}$ for $S$ sufficiently large (since, otherwise, equation (A8) would not hold). Clearly, in any period following the deviation, the deviant firm's profit is at least zero. Hence, a necessary condition for the deviation to be unprofitable is

$$
S\left(1-\frac{\left(u_{\hat{t}} / u^{\prime}\right)}{\frac{1}{n_{\hat{t}}-1}\left(u_{\hat{t}} / u^{\prime}\right)+1}\right)^{2}-\left[\left(u^{\prime}\right)^{\beta}-u_{\widehat{t}}^{\beta}\right] \leq \frac{S}{(1-\delta) n_{\widehat{t}}^{2}},
$$

where the first term on the left-hand side is the deviant firm's profit in the period of deviation, the second term the additional investment cost associated with the higher quality, while the term on the right-hand side is an upper bound on the discounted sum of gross profits along the equilibrium path. The inequality can be rewritten as

$$
\frac{1}{(1-\delta) n_{\hat{t}}^{2}} \geq\left(1-\frac{\left[u_{\hat{t}}^{\beta} / S\right]^{1 /(\beta+1)}}{\frac{1}{n_{\hat{t}}-1}\left[u_{\hat{t}}^{\beta} / S\right]^{1 /(\beta+1)}+1}\right)^{2}-\left(\left[u_{\hat{t}}^{\beta} / S\right]^{1 /(\beta+1)}-\left[u_{\hat{t}}^{\beta} / S\right]\right)
$$

Hence, in equilibrium, equations (A8) and (A9) must hold for any $\widehat{t}$ (at which entry occurs) and any $S$ sufficiently large. For notational convenience, I will henceforth drop the time subscript. As mentioned above, I will prove the proposition by contradiction. Suppose that the number of active firms $n \rightarrow \infty$ as $S \rightarrow \infty$. Hence, the left-hand side of both equations (A8) and (A9) will tend to zero as market size becomes large. For equation (A8) to hold, I therefore must have $u^{\beta} / S \rightarrow 0$ as $S \rightarrow \infty$. But if $u^{\beta} / S \rightarrow 0$, then the r.h.s. of equation (A9) will converge to one as market size becomes large. That is, equation (A9) cannot hold for $S$ large. A contradiction.

\section{References}

Besanko, D. ANd Doraszelski, U. "Capacity Dynamics and Endogenous Asymmetries in Firm Size.” RAND Journal of Economics, Vol. 35 (2004), pp. 23-49.

Budd, C., Harris, C., And Vickers, J. "A Model of the Evolution of Duopoly: Does the Asymmetry Between Firms Tend to Increase or Decrease?” Review of Economic Studies, Vol. 60 (1993), pp. 543-573.

Cabral, L. And Riordan, M. "The Learning Curve, Market Dominance, and Predatory Pricing.” Econometrica, Vol. 62 (1994), pp. 1115-1140.

Cohen, W.M. and Levinthal, D.A. "Innovation and Learning: The Two Faces of R\&D.” Economic Journal, Vol. 99 (1989), pp. 569-596.

D’Aspremont, C. And Jacquemin, A. “Cooperative and Noncooperative R\&D in Duopoly with Spillovers.” American Economic Review, Vol. 78 (1988), pp. 1133-1137.

De BondT, R. "Spillovers and Innovative Activities.” International Journal of Industrial Organization, Vol. 15 (1997), pp. 1-28.

De Roos, N. “A Model of Collusion Timing." International Journal of Industrial Organization, Vol. 22 (2004), pp. 351-387.

Doraszelski, U. and Markovich, S. “Advertising Dynamics and Competitive Advantage.” Working Paper, Department of Economics, Harvard University, 2005.

DutTA, P.K. “A Folk Theorem for Stochastic Games.” Journal of Economic Theory, Vol. 66 (1995), pp. 1-32.

ERICSON, R. AND PaKes, A. "Markov-Perfect Industry Dynamics: A Framework for Empirical Work.” Review of Economic Studies, Vol. 62 (1995), pp. 53-82.

Evans, D.S. AND Schmalensee, R. "Some Economic Aspects of Antitrust Analysis in Dynamically Competitive Industries.” NBER Working Paper no. 8268, National Bureau of Economic Research, 2001.

Fershtman, C. And Pakes, A. "A Dynamic Oligopoly with Collusion and Price Wars.” RAND Journal of Economics, Vol. 31 (2000), pp. 207-236.

Fudenberg, D. AND Tirole, J. "Capital as a Commitment: Strategic Investment to Deter Mobility.” Journal of Economic Theory, Vol. 31 (1983), pp. 227-250.

- Game Theory. Cambridge, Mass.: MIT Press, 1991.

(c) RAND 2007. 
Gowrisankaran, G. “A Dynamic Model of Endogenous Horizontal Mergers.” RAND Journal of Economics, Vol. 30 (1999), pp. 56-83.

Hole, A. Dynamic Non-Price Strategy and Competition: Models of R\&D, Advertising and Location. Ph.D. dissertation, Department of Economics, London School of Economics, 1997.

Kamien, M.I., Muller, E., And ZAng, I. "Research Joint Ventures and R\&D Cartels.” American Economic Review, Vol. 82 (1992), pp. 1293-1306.

Kesteloot, K. AND Veugelers, R. "Stable R\&D Cooperation with Spillovers." Journal of Economics and Mangement Strategy, Vol. 4 (1995), pp. 651-672.

Kwoka, J.E.J. And White, L.J., eds. The Antitrust Revolution. 4th ed. New York: Oxford University Press, 2004.

Maskin, E. And Tirole, J. "A Theory of Dynamic Oligopoly I: Overview and Quantity Competition with Large Fixed Costs." Econometrica, Vol. 56 (1988), pp. 549-570.

Morse, M.H. "Vertical Mergers: Recent Learning.” Business Lawyer, Vol. 53 (1998), pp. 1217-1248.

Nerlove, M. And Arrow, K.J. "Optimal Advertising Policy Under Dynamic Conditions.” Economica, Vol. 29 (1962), pp. 129-142.

NocKE, V. “Underinvestment and Market Structure.” STICERD Discussion Paper no. EI/22, London School of Economics, 1998.

Reinganum, J. “The Timing of Innovation: Research, Development, and Diffusion.” In R. Schmalensee and R.D. Willig, eds., The Handbook of Industrial Organization, Vol. 1. New York: North-Holland, 1989.

REYNoldS, S.S. "Capacity Investment, Preemption and Commitment in an Infinite Horizon Model." International Economic Review, Vol. 28 (1987), pp. 69-88.

- "Dynamic Oligopoly with Capacity Adjustment Costs." Journal of Economic Dynamics and Control, Vol. 15 (1991), pp. 491-514.

Segal, I. And Whinston, M.D. “Antitrust in Innovative Industries.” Working Paper, Department of Economics, Stanford University, and Department of Economics, Northwestern University, 2003.

Shaked, A. AND Sutton, J. “Natural Oligopolies.” Econometrica, Vol. 51 (1983), pp. 1469-1484.

- AND . "Product Differentiation and Industrial Structure." Journal of Industrial Economics, Vol. 36 (1987), pp. 131-146.

ShapIro, C. "Theories of Oligopoly Behavior.” In R. Schmalensee and R.D. Willig, eds., The Handbook of Industrial Organization, Vol. 1. New York: North-Holland, 1989.

SutTon, J. Sunk Costs and Market Structure. Cambridge, Mass.: MIT Press, 1991.

. Technology and Market Structure. Cambridge, Mass.: MIT Press, 1998.

. "Market Structure: Theory and Evidence." In M. Armstrong and R. Porter, eds., The Handbook of Industrial Organization, Vol. 3, New York: North Holland, forthcoming. 